\title{
Bursicon Functions within the Drosophila CNS to Modulate Wing Expansion Behavior, Hormone Secretion, and Cell Death
}

\author{
Nathan C. Peabody, ${ }^{1 \star}$ Fengqiu Diao, ${ }^{1 \star}$ Haojiang Luan, ${ }^{1}$ Howard Wang, ${ }^{1}$ Elizabeth M. Dewey, ${ }^{2}$ Hans-Willi Honegger, ${ }^{2}$ \\ and Benjamin $\mathrm{H}$. White ${ }^{1}$ \\ ${ }^{1}$ Laboratory of Molecular Biology, National Institute of Mental Health, National Institutes of Health, Bethesda, Maryland 20892, and ${ }^{2}$ Department of \\ Biological Sciences, Vanderbilt University, Nashville, Tennessee 37325
}

\begin{abstract}
Hormones are often responsible for synchronizing somatic physiological changes with changes in behavior. Ecdysis (i.e., the shedding of the exoskeleton) in insects has served as a useful model for elucidating the molecular and cellular mechanisms of this synchronization, and has provided numerous insights into the hormonal coordination of body and behavior. An example in which the mechanisms have remained enigmatic is the neurohormone bursicon, which, after the final molt, coordinates the plasticization and tanning of the initially folded wings with behaviors that drive wing expansion. The somatic effects of the hormone are governed by bursicon that is released into the blood from neurons in the abdominal ganglion (the $\mathrm{B}_{\mathrm{AG}}$ ), which die after wing expansion. How bursicon induces the behavioral programs required for wing expansion, however, has remained unknown. Here we show by targeted suppression of excitability that a pair of bursicon-immunoreactive neurons distinct from the $B_{A G}$ and located within the subesophageal ganglion in Drosophila (the $B_{\mathrm{SEG}}$ ) is involved in controlling wing expansion behaviors. Unlike the $\mathrm{B}_{\mathrm{AG}}$, the $\mathrm{B}_{\mathrm{SEG}}$ arborize widely in the nervous system, including within the abdominal neuromeres, suggesting that, in addition to governing behavior, they also may modulate the $B_{A G}$. Indeed, we show that animals lacking bursicon receptor function have deficits both in the humoral release of bursicon and in posteclosion apoptosis of the $\mathrm{B}_{\mathrm{AG}}$. Our results reveal novel neuromodulatory functions for bursicon and support the hypothesis that the $\mathrm{B}_{\mathrm{SEG}}$ are essential for orchestrating both the behavioral and somatic processes underlying wing expansion.
\end{abstract}

Key words: ecdysis; eclosion; network; circuit; apoptosis; Drosophila

\section{Introduction}

Hormones are major determinants of behavior and often ensure congruence of an animal's actions and physiological state by exerting their effects both on the brain and on other tissues. The coordination of somatic changes and behavior is particularly evident in the developmental process of ecdysis, in which a growing insect must shed its exoskeleton and expand and harden a new one [for review, see Truman (2005), Ewer (2007), and Zitnan et al. (2007)]. Adult ecdysis in winged insects additionally involves the hormonally mediated deployment of the wings, which are not expanded until this stage. This requires synchronizing physiological changes in the wing cuticle with behaviors designed to increase internal pressure and drive blood into the wings to expand them (Fraenkel et al., 1984). The hardening of the expanded wings marks the end of morphological development and is fol-

Received June 20, 2008; revised Nov. 9, 2008; accepted Nov. 12, 2008.

This work was supported by the Intramural Research Program of the National Institute of Mental Health. We thank Aaron Hsueh, John Ewer, and John Carlson for reagents, the Bloomington Stock Center for fly lines, and Howard Nash, Grace Gray, and anonymous reviewers for constructive comments on this manuscript.

${ }^{*} N$.C.P. and F.D. contributed equally to this work.

Correspondence should be addressed to Benjamin H. White, National Institute of Mental Health, National Institutes of Health, 9000 Rockville Pike, Bethesda, MD 20892. E-mail: benjaminwhite@mail.nih.gov.

DOI:10.1523/JNEUROSCI.2842-08.2008

Copyright $\odot 2008$ Society for Neuroscience $\quad$ 0270-6474/08/2814379-13\$15.00/0 lowed by the remarkable destruction of cells and tissues that support ecdysis (Cottrell, 1962b; Kimura and Truman, 1990; Draizen et al., 1999), a process that is also known to be hormonally dependent (Truman et al., 1992).

The neurohormone bursicon has emerged as a central player in orchestrating the final steps of adult ecdysis. Evidence from multiple insects indicates that neurons in the abdominal ganglia are the source of the blood-borne hormone, which mediates multiple changes in cuticle properties that support wing expansion (Fraenkel and Hsiao, 1965; Mills et al., 1965; Truman, 1973; Luan et al., 2006). These include cuticle plasticization (Cottrell, 1962c; Reynolds, 1977), apoptosis of the wing epidermis (Kimura et al., 2004), and tanning, or hardening, of the expanded wings (Cottrell, 1962a; Fraenkel and Hsiao, 1962). Genetic evidence from Drosophila confirms bursicon's essential role in wing expansion (Dewey et al., 2004), including behavior, in that mutants defective for the bursicon receptor, which is encoded by the rickets gene, do not swallow air or tonically contract their abdomens (Baker and Truman, 2002). These two motor patterns act in concert to force hemolymph into the wings to unfold them (Fraenkel et al., 1984). Whether these behaviors require hormone derived from the bursicon-expressing neurons in the abdominal nervous system or from some other source has remained unknown.

In addition to seven bilaterally represented pairs of neurons in 
the abdominal ganglion $\left(\mathrm{B}_{\mathrm{AG}}\right)$, adult Drosophila consistently express bursicon in a pair of neurons in the subesophageal ganglion $\left(\mathrm{B}_{\mathrm{SEG}}\right)$ before wing expansion. Here, we examine the function and anatomy of both the $\mathrm{B}_{\mathrm{AG}}$ and $\mathrm{B}_{\mathrm{SEG}}$ using a combination of techniques, including targeted suppression of excitability, singlecell labeling, and mutant analysis. We identify the $\mathrm{B}_{\mathrm{SEG}}$ as the source of bursicon required for wing expansion behaviors and demonstrate that, unlike the $\mathrm{B}_{\mathrm{AG}}$, they arborize throughout the CNS, including within the abdominal neuromeres. We provide evidence from rickets mutants that centrally derived bursicon is likely to modulate bursicon release from the $\mathrm{B}_{\mathrm{AG}}$ and also facilitate the postexpansional death of the latter neurons. Our results thus suggest a mechanism for the coordination of bursiconmediated processes in wing expansion and support a neuromodulatory role for bursicon in the apoptotic processes that follow the terminal ecdysis event.

\section{Materials and Methods}

Fly culture/crosses. All flies were grown on corn meal-molasses medium and maintained at $25^{\circ} \mathrm{C}$ in a constant $12 \mathrm{~h}$ light-dark cycle. Wild-type flies (Canton S strain) and rickets ${ }^{4}$ mutants were from the Bloomington Stock Center (Indiana University). The $\mathrm{w}^{1118}$ line was a gift from Howard Nash (National Institute of Mental Health, Bethesda, MD). The Gal4 driver lines used (yw; + CCAP-Gal4, yw;CCAP-Gal4;+, w;CCAPGal4;+, and w;c929-Gal4;+) have been described previously (O’Brien and Taghert, 1998; Park et al., 2003; Luan et al., 2006), as have the $1 \times$, $2 \times$, and $3 \times$ EKO lines (White et al., 2001).

Burs-Gal4 constructs and transgenic Drosophila lines. PCR primers (P252F 5'-TGATTAGCCAATAAGTTGTGAGG-3' and P252R 5'CTCGTCGGCCCGACTGCGA-3') were designed to amplify the 252 bp region between the ATG start codon of burs and the stop codon of the nearest predicted coding sequence upstream of it. The PCR product containing this putative burs promoter fragment was cloned using the TOPO TA cloning kit (Invitrogen) and sequenced using Big Dye chemistry (Applied Biosystems) before being subcloned into the EcoRI site of the Gal4 vector, pG4PN (gift from John Carlson's laboratory, Yale University, New Haven, CT) and sequenced to check for correct orientation. Five transgenic lines were created by standard P-element transformation performed by Model System Genomics (Duke University). One of these lines, P12, with an insert on the second chromosome was used in the work described here.

Immunohistochemistry and confocal microscopy. For analysis of wholemount nervous system preparations, eclosed adults, stage P15i pharate adults [i.e., with black wings and meconium patch visible (Bainbridge and Bownes, 1981)] or wandering third-instar larvae were dissected in PBS, and the excised nervous systems were fixed in $4 \%$ paraformaldehyde in PBS for 20-30 min, followed by postfixation in 4\% paraformaldehyde/PBS plus $0.5 \%$ Triton X-100 for $15 \mathrm{~min}$. Procedures for immunostaining were as previously described (Luan et al., 2006). Rabbit antibursicon $\alpha$-subunit (anti-burs) antibodies were used at 1:5000 dilution, and mouse anti-bursicon $\beta$-subunit (anti-pburs; gift from Aaron Hsueh, Stanford University, Stanford, CA) were used at 1:500. Secondary antibodies (AlexaFluor 488 goat anti-rat, AlexaFluor 568 goat anti-rabbit, and AlexaFluor 680 goat anti-mouse, all from Invitrogen) were used at 1:500 dilution. Confocal imaging was performed using a Nikon C-1 confocal microscope. $Z$-series through either the brain or ventral nerve cord of each sample were acquired in $1 \mu \mathrm{m}$ increments using a $20 \times$ objective unless otherwise noted, using $488 \mathrm{~nm}, 543 \mathrm{~nm}$, and $633 \mathrm{~nm}$ laser emission lines for fluorophore excitation. Unless otherwise noted, the images shown are maximal projections of the volume rendered $z$-stacks of confocal sections taken through the entire nervous system.

Analysis of immunostaining and cell death. For preparations used to examine $\mathrm{B}_{\mathrm{SEG}}$ and $\mathrm{B}_{\mathrm{AG}}$ fiber staining, animals were briefly anesthetized under $\mathrm{CO}_{2}$, immersed in $100 \% \mathrm{ETOH}$, and then pinned out and filleted from the dorsal side in PBS. The head and internal organs were removed before fixation and staining. Confocal $Z$-series, which avoided image planes containing body wall, were acquired using a $20 \times$ objective, and identical acquisition parameters, calibrated on preparations from 5 min posteclosion animals to ensure that the fluorescence signals were not saturating, were used for all preparations. For quantitation of immunostaining, grayscale, volume-rendered images of the $Z$-stacks were inverted using Adobe Photoshop (Adobe Systems), and mean pixel values were calculated for a $400 \times 400$ pixel square centered over the abdominal nerves immediately after the exit point from the abdominal ganglion, or for a $200 \times 200$ pixel square centered over the rostral portion of the second thoracic segment, T2. Fibers in these regions were uniformly well preserved in all preparations. Mean background pixel values (calculated for each image from a $200 \times 200$ pixel field outside of the imaged preparation) were subtracted to derive the "mean pixel intensities" used as a measure of bursicon immunoreactivity for each preparation. Statistical analysis of the means was performed by $t$ test (two-sample assuming unequal variances).

For analysis of cell death, newly emerged flies were collected within 10 min of eclosion and killed 6, 14, 24, or $48 \mathrm{~h}$ later for staining of the CNS with anti-burs antibody as described above. At least six preparations were analyzed at each time point by confocal microscopy, and surviving cells were identified from analysis of multiple image planes of confocal $Z$-series, in which they could easily be distinguished from cellular debris, which typically formed smaller immunoreactive spots. To detect DNA fragmentation as a marker of apoptosis, TUNEL was performed on CNS preparations excised from animals killed $6 \mathrm{~h}$ after eclosion. After immunostaining with anti-burs antibody, these preparations were washed $2 \times$ 10 min with TUNEL dilution buffer and labeled using the In Situ Cell Death Detection Kit, TMR Red (Roche Applied Science). The labeling reaction was performed for $3 \mathrm{~h}$ at $37^{\circ} \mathrm{C}$. Imaging of the preparations was done by confocal microscopy, collecting $Z$-series through the ventral nerve cord of each sample in $1 \mu \mathrm{m}$ increments using a $20 \times$ objective.

Analysis of expression patterns. The expression pattern of EGFP driven by Burs-Gal4 and c929-Gal4 varied somewhat between individuals, as did the patterns of bursicon immunoreactivity. To represent the intensity and frequency of labeling of individual identified neurons with each driver, we created consensus expression patterns derived from multiple CNS preparations of each genotype. To determine the consensus pattern for Burs-Gal4>UAS-EGFP expression, we double labeled multiple preparations with anti-burs antibodies. The fluorescence intensity of each EGFP-positive soma in each preparation was scored on a scale of 1-3 and its identity determined based on overlapping bursicon immunolabeling. The consensus intensity value $(I)$ for a given neuron was calculated by averaging all nonzero values for this neuron across preparations. The frequency $(v)$ with which a given neuron was labeled was calculated by dividing the number of preps in which that neuron had a nonzero labeling intensity by the total number of preparations. The same procedure was used to generate consensus patterns for animals expressing the GFPtagged EKO transgene.

Manipulation of neuronal function and scoring of phenotypes. Crosses between Gal4 driver and UAS-effector lines were typically set up with parallel control crosses of the driver to $\mathrm{w}^{1118} ;+;+$ or Canton S. Wing phenotypes of at least 100 individuals were scored at least $24 \mathrm{~h}$ after eclosion as described previously (Luan et al., 2006). Flies were scored as "unexpanded" (UEW) if the distal tip of the folded wing had assumed an angle of $\angle 90^{\circ}$ relative to the proximal portion of the wing and as "expanded" (EW) if they had fully unfolded. Flies with partially expanded wings (PEW) had intermediate wing morphologies. Interestingly, most Burs-Gal4 $>2 \times \mathrm{EKO}$ animals had partially expanded wings, but typically also exhibited a novel "bubble wing" phenotype not observed previously in suppression experiments with CCAP-Gal4 $>2 \times$ UAS-EKO. In the most overt cases, hemolymph appeared to fill the wings like small balloons.

The TARGET system (McGuire et al., 2004) using temperaturesensitive Gal80 $\left(\mathrm{Gal} 80^{\mathrm{ts}}\right)$ was used to temporally regulate UAS-Kir2.1 transgene expression. Experimental animals were reared at $18^{\circ} \mathrm{C}$, collected at the third-instar wandering stage, and placed into individual food vials. These larvae pupated at $18^{\circ} \mathrm{C}$ and were transferred at various times after puparium formation (APF) to $31^{\circ} \mathrm{C}$ to complete development. Experiments in which EKO-mediated suppression was controlled by temperature shift were conducted in a similar manner on animals expressing $1 \times \mathrm{EKO}$ in the absence of $\mathrm{Gal} 80^{\mathrm{ts}}$. 


\section{$3^{\text {rd }}$ Instar}
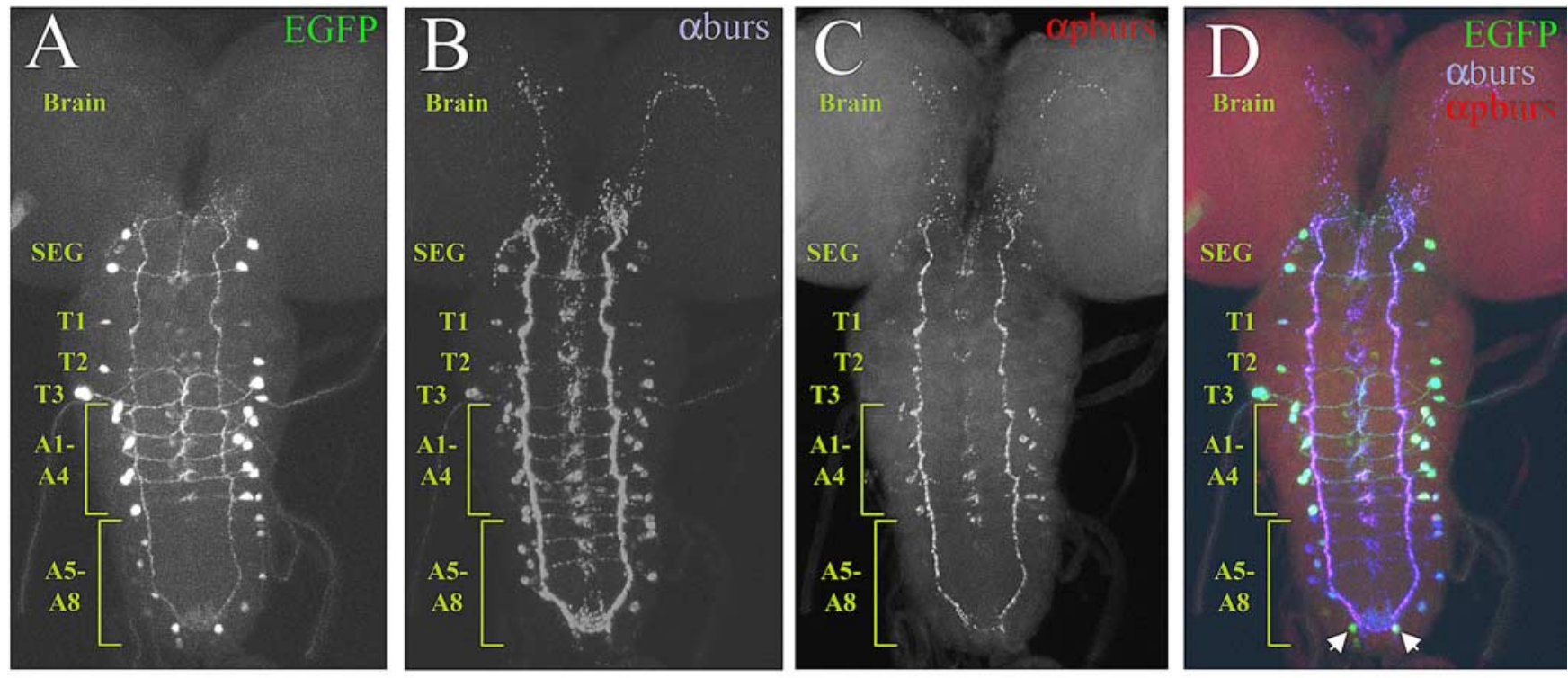

\section{Adult}
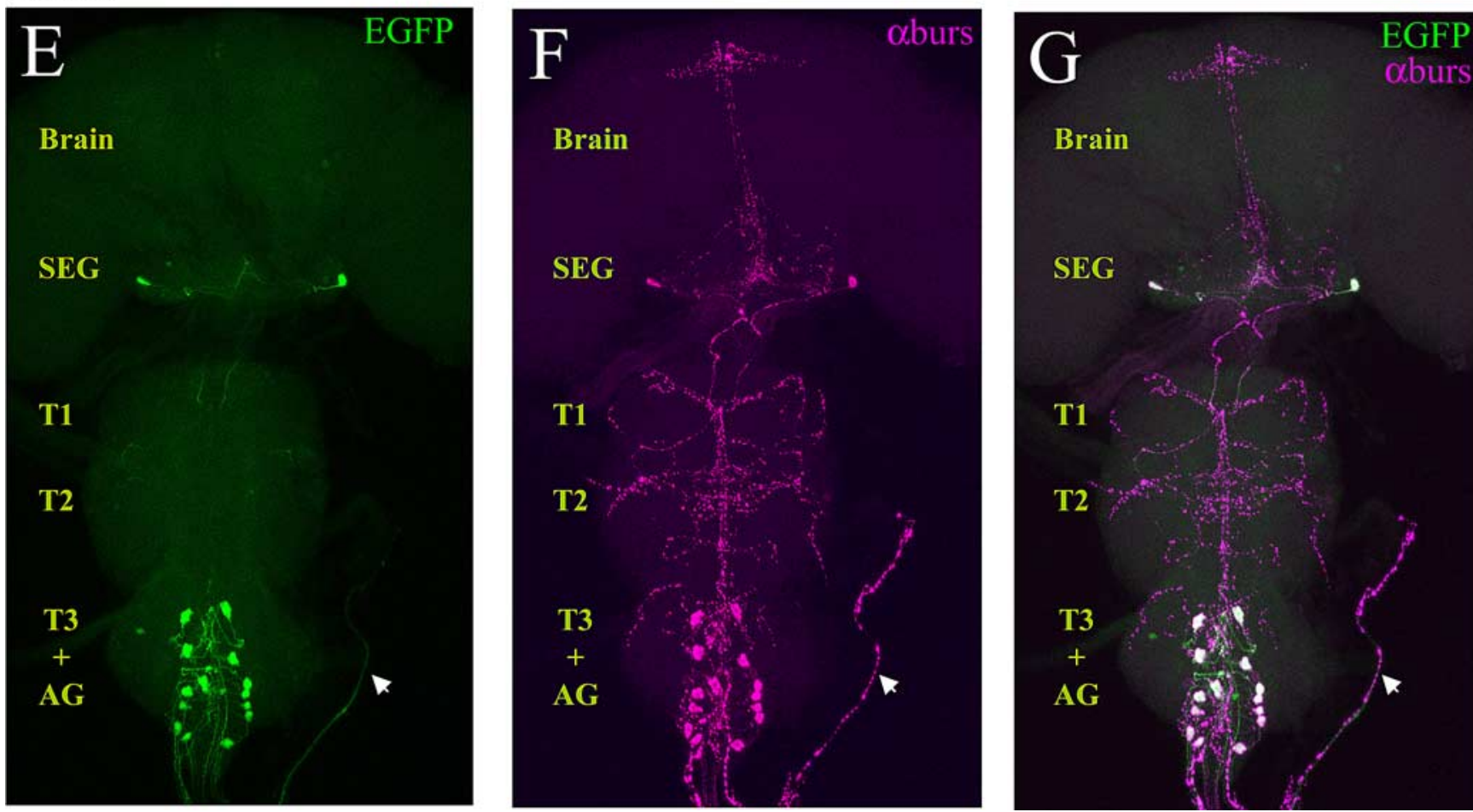

Figure 1. Expression of Burs-Gal4 mimics the expression pattern of bursicon $\alpha$-subunit (burs) in both larval and adult nervous systems. Confocal images of nervous system whole mounts from Burs-Gal4 > UAS-EGFP animals at the third larval instar and adult stages. $\boldsymbol{A}-\boldsymbol{D}$, Larval nervous system expressing EGFP under the control of Burs-Gal4 ( $\boldsymbol{A}$ ), triple labeled with antibodies to both burs $(\boldsymbol{B})$ and pburs $(\boldsymbol{C}$. In the merged image $(\boldsymbol{D})$, the green, blue, and red channels represent EGFP, burs, and pburs labeling, respectively. Neurons immunopositive for burs are consistently labeled with EGFP. These include the following: two prominent pairs of neurons in the subesophageal ganglion; one pair in each of the first two thoracic neuromeres and two pairs in the third; two pairs of neurons in each of the first four abdominal neuromeres; and one to two pairs in each of the remaining abdominal neuromeres. Arrows indicate two neurons in the terminal abdominal segment that are labeled by Burs-Gal4, but which do not express burs. In contrast to burs, pburs expression is prominent only in the first four abdominal segments, with weak labeling in some of the bursimmunopositive subesophageal neurons. SEG, Subesophageal ganglion; T1-3, thoracic neuromeres 1-3; A1-8, abdominal neuromeres 1-8. E-G, Adult nervous system from a newly eclosed Burs-Gal4 > UAS-EGFP animal expressing EGFP ( $\boldsymbol{E}$, green), double labeled with burs antibodies ( $\boldsymbol{F}$, magenta). $\boldsymbol{G}$, Merged image shows complete correspondence of labeling, with overlapping labels appearing as white. Whole mounts are oriented symmetrically along the rostral-caudal axis with the midline of the nervous system in the center. Arrow, An intact section of abdominal nerve. AG, Abdominal ganglion.

Abdominal contraction and air swallowing. Experimental animals were isolated as wandering third-instar larvae and transferred to individual food vials to complete development. These animals were observed by eye or videotaped upon eclosion and evaluated for sustained abdominal con- traction lasting at least $10 \mathrm{~min}$. This behavior, which is essential for wing expansion, consists of pronounced elongation of the abdomen, typically accompanied by downward flexion. Air swallowing was quantified by measuring the volume of air in the gut of the fly. Flies were briefly im- 
A

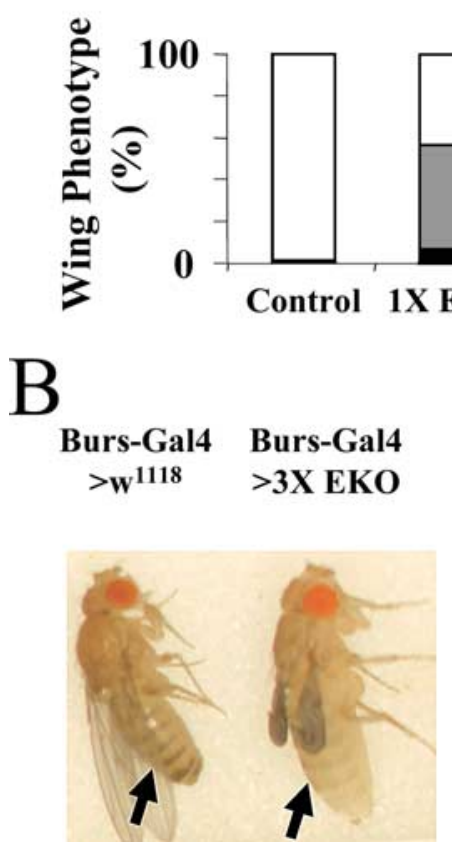

\section{Results}

Development of a Gal4 driver that

expresses selectively in

bursicon-expressing neurons

Bursicon-expressing neurons $\left(\mathrm{N}_{\text {Burs }}\right)$ in adult Drosophila are a subset of the cells that express the neuropeptide CCAP (crustacean cardioactive peptide). We have shown previously that both wing expansion and bursicon release into the hemolymph can be suppressed in newly eclosed adults by expressing three copies of the transgene encoding the suppressor $\mathrm{K}^{+}$-channel UAS-EKO using the CCAPGal4 driver line (Luan et al., 2006). Our evidence suggested that this manipulation inhibited wing expansion by suppressing not only $\mathrm{N}_{\text {Burs, }}$, but also neurons that regulate secretion of the hormone without expressing it. To determine the effect of suppressing only neurons in $\mathrm{N}_{\text {Burs }}$, we therefore designed a driver line that would permit UAStransgene expression solely in this set of neurons. We used the putative promoter/enhancer region of the gene encoding the bursicon $\alpha$-subunit (also known as burs) to drive expression of Gal4 in bursiconexpressing neurons in transgenic flies as described in Materials and Methods. We obtained two Burs-Gal4 lines that expressed with high fidelity in $\mathrm{N}_{\text {Burs }}$, one of which we used in the present study (Fig. 1).

As shown in Figure $1, A, B$, and $D$, BursGal4-driven UAS-EGFP expression in the CNS of the third larval stage largely overlaps with the pattern of immunoreactivity

mersed in $100 \%$ ethanol to free the cuticle and bristles of air, then submerged in glycerol. The legs and wings were removed under a dissection microscope, and the gut exposed by an incision up the midline of the fly. The air was released by opening the gut membrane and the liberated bubble was photographed as it rose to the surface. Air volume was calculated from the diameter of the bubble assuming spherical geometry, using ImageJ software (W. S. Rasband, United States National Institutes of Health, Bethesda, MD, http://rsb.info.nih.gov/ij/) calibrated with a 2 $\mathrm{mm}$ micrometer. Air volume was measured at the end of wing expansion or, in cases in which this was absent, $90 \mathrm{~min}$ after the eclosion time.

Labeling of single neurons. Individual $\mathrm{B}_{\mathrm{AG}}$ and $\mathrm{B}_{\mathrm{SEG}}$ neurons were labeled using the Flp-out mCD8-GFP method (Wong et al., 2002) and the Burs-Gal4 driver. Eggs from yw, hs-Flp;Burs-Gal4;UAS-stop-mCD8GFP animals were collected for $24 \mathrm{~h}$ at $25^{\circ} \mathrm{C}$, heat shocked at $37^{\circ} \mathrm{C}$ for $1 \mathrm{~h}$, and then returned to $25^{\circ} \mathrm{C}$ for development. The nervous systems of pharate adults were double immunolabeled with rat anti-mouse CD8 (Ly-Z) (1:200 dilution, CALTAG Laboratories, Invitrogen) and rabbit anti-burs antibodies using AlexaFluor 488 and AlexaFluor 568 as secondary antibodies

Hemolymph collection and immunoblotting. Hemolymph was collected from flies within $1 \mathrm{~h}$ of eclosion as previously described (Luan et al., 2006). Approximately 6-10 flies were required to collect $500 \mathrm{nl}$ of hemolymph, which were electrophoresed on $12-4 \%$ gradient Tris- $\mathrm{HCl}$ minigels before transfer to $0.2 \mu \mathrm{m}$ nitrocellulose membranes (Bio-Rad). Detection was accomplished using anti-burs antibodies at a 1:5000 dilution, peroxidase-conjugated goat anti-rabbit secondary antibody $(10 \mu \mathrm{g} / \mathrm{ml}$, Pierce) diluted 1:2000, and incubation with West Femto chemiluminescent substrate (Pierce) for $5 \mathrm{~min}$, before development on BioMax film (Eastman Kodak) for $10 \mathrm{~min}$. obtained by staining with an anti-burs antibody. As has been reported previously (Dewey et al., 2004; Zhao et al., 2008), expression of the burs gene at this stage is quite broad and includes pairs of neurons in the subesophageal, thoracic, and abdominal neuromeres. Weak expression is also often observed in a pair of neurons in the brain (data not shown). The expression pattern of the bursicon $\beta$-subunit (also known as pburs) is restricted to a subset of cells in the abdominal segments (Fig. $1 C, D$ ), indicating that the bursicon hormone, which is formed by the burs/pburs heterodimer, is also restricted at this stage, as has been noted before (Luo et al., 2005). Most of the neurons that express the burs subunit alone are also CCAP immunopositive (data not shown) and are included in the pattern of Burs-Gal4 expression.

The pattern of burs expression becomes more restricted in the pharate adult (Fig. $1 E-G$ ), and, as has been noted previously, coincides completely with the expression pattern of pburs (Luan et al., 2006). At this stage, which just precedes wing expansion, there are typically 14 bursicon-expressing neurons (the $\mathrm{B}_{\mathrm{AG}}$ ) in the abdominal ganglion, and two posteriorly disposed neurons (the $\mathrm{B}_{\mathrm{SEG}}$ ) in the subesophageal ganglion. In some preparations two additional subesophageal neurons are also seen to express GFP and label with anti-burs antibodies, consistent with our previous observations. This is reflected in consensus patterns showing the frequency and intensity of UAS-EGFP expression in multiple preparations (supplemental Fig. S1, available at www. jneurosci.org as supplemental material). 

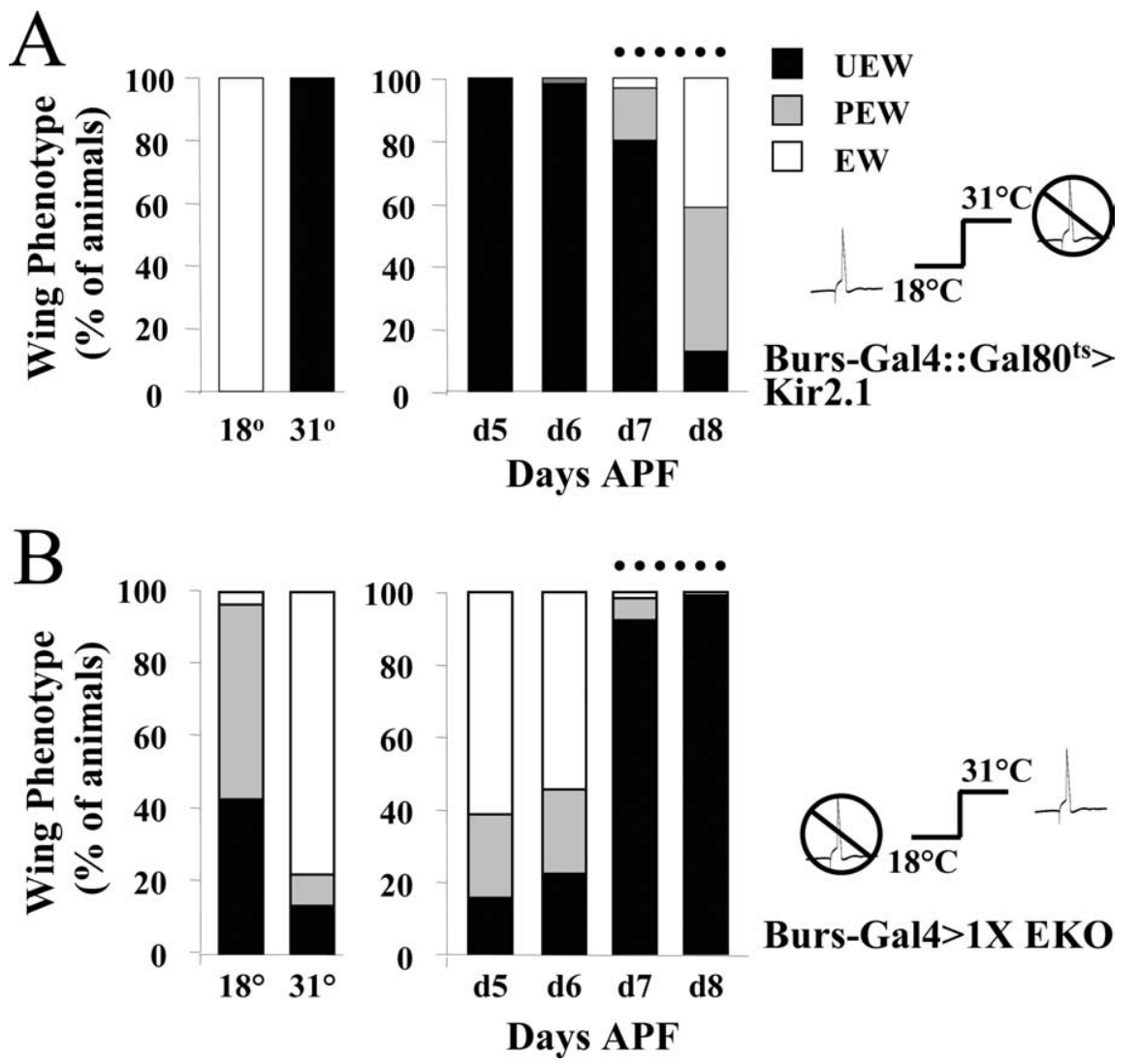

Figure 3. Suppression of neuronal excitability in $\mathrm{N}_{\text {Burs }}$ blocks wing expansion by acting late in development. $\boldsymbol{A}, \boldsymbol{B}$, Bar graphs showing the frequency of wing expansion deficits in either Burs-Gal4::Gal80ts $>$ UAS-Kir2.1 animals $(\boldsymbol{A})$ or Burs-Gal4 $>1 \times$ UAS-EKO animals $(\boldsymbol{B})$ when raised at constant temperatures of $18^{\circ} \mathrm{C}$ or $31^{\circ} \mathrm{C}$ (left) or when shifted from $18^{\circ} \mathrm{C}$ to $31^{\circ} \mathrm{C}$ at the indicated times during development (right). Times of temperature shift are indicated in days after puparium formation (APF), measured at $18^{\circ} \mathrm{C}$. In $\boldsymbol{A}$, excitability is expected to be suppressed at $31^{\circ} \mathrm{C}$ as Gal $80^{\text {ts }}$ is inactive at this temperature, and Gal4 drives Kir2.1 expression. The opposite is true in $\boldsymbol{B}$, where the efficacy of the EKO channel is reduced at $31^{\circ} \mathrm{C}$ relative to $18^{\circ} \mathrm{C}$. In both cases, dotted lines indicate the developmental period during which the temperature shift becomes ineffective in reversing the wing expansion phenotype associated $18^{\circ} \mathrm{C}$. The state of $\mathrm{N}_{\text {Burs }}$ excitability during (or just before) this period therefore determines the ability of the animals to expand their wings. The action potential icon (open or crossed out) indicates whether or not $\mathrm{N}_{\text {Burs }}$ are predicted to be excitable at the indicated temperature.

\section{Suppression of excitability of bursicon-expressing neurons} using Burs-Gal4 blocks bursicon release and wing expansion We have shown before that graded suppression of excitability in CCAP-expressing neurons $\left(\mathrm{N}_{\mathrm{CCAP}}\right)$, achieved by expressing increasing copy numbers of the UAS-EKO transgene, gives rise to incrementally more severe wing expansion deficits. As shown in Figure $2 A$, these same manipulations made using the Burs-Gal4 driver yield a similar distribution of phenotypes. Most of the flies expressing a single copy of the UAS-EKO transgene in $\mathrm{N}_{\text {Burs }}$ show a partially expanded wing phenotype, in which the wing remains partly folded. Approximately $40 \%$ of flies, however, expand their wings fully, and only a small fraction has completely unexpanded wings. In contrast, most flies expressing three copies of the UASEKO transgene fail to expand their wings. This result is also obtained by expressing a single copy of the more potent $\mathrm{K}^{+}$-channel suppressor, UAS- $\mathrm{K}_{\mathrm{ir}} 2.1$, which, in addition, causes pupal lethality in nearly half of animals (170 of 371 total). Lethality is likely a consequence of broad Kir2.1 expression during the larval and early pupal stages, as animals expressing Kir2.1 throughout $\mathrm{N}_{\mathrm{C}^{-}}$ CAP die during pupal development (Luan et al., 2006).

The failure of Burs-Gal4>3× UAS-EKO flies to expand their wings is consistent with the inhibition of bursicon release in these animals. Supporting the conclusion that bursicon is not secreted into the hemolymph is the observation that these animals failed to tan rapidly (Fig. $2 B$ ), typically retaining their unpigmented, juvenile phenotype $3 \mathrm{~h}$ after eclosion $(n=11)$. We directly confirmed the absence of bursicon in the hemolymph by Western blot (Fig. 2C). In contrast to wildtype Canton $\mathrm{S}$ animals, or control flies bearing the Burs-Gal4 transgene only, Burs-Gal4 $>3 \times$ UAS-EKO animals had no detectable bursicon in their hemolymph $1 \mathrm{~h}$ after eclosion. As we have shown previously, a similar result is obtained when three copies of UAS-EKO are driven by the c929-Gal4 driver (Fig. 2C), a manipulation that suppresses the $\mathrm{B}_{\mathrm{AG}}$ neurons, but not the $\mathrm{B}_{\mathrm{SEG}}$ (Luan et al., 2006).

Inhibition of wing expansion observed with Burs-Gal4 does not result from developmental suppression of excitability

As noted above, the effects of strongly suppressing the excitability of $\mathrm{N}_{\text {Burs }}$ are similar to those observed when all $\mathrm{N}_{\mathrm{CCAP}}$ neurons are suppressed. Because the Burs-Gal4 driver expresses in most CCAP-expressing neurons during development, it was possible that the failure to release bursicon in adult animals, and the concomitant wing expansion deficits, were the result of developmental suppression of $\mathrm{N}_{\mathrm{CCAP}}$ and not the acute suppression of $\mathrm{N}_{\text {Burs }}$ after eclosion. To exclude this possibility, we used a combination of techniques to temporally restrict the period of suppression during development. First, we used the Gal80 ${ }^{\text {ts }}$ based TARGET system (McGuire et al., 2004) to restrict expression of UAS-Kir2.1 to the postlarval period.

As shown in Figure $3 A$, flies grown at a constant temperature of $18^{\circ} \mathrm{C}$ had no wing expansion deficits. This result is expected because at this temperature Gal $80^{\text {ts }}$ constitutively inhibits Gal4 activity and UAS-Kir2.1 is not expressed. In contrast, flies grown at $31^{\circ} \mathrm{C}$ constant temperature failed to expand their wings. Again, this is the anticipated result because $\mathrm{Gal} 0^{\mathrm{ts}}$ is inactive at this temperature and Gal4 will drive expression of Kir2.1 in $\mathrm{N}_{\text {Burs }}$. However, the number of flies completing development at the higher temperature was very low. As noted above, this is likely a consequence of the broad expression of the Burs-Gal4 driver in $\mathrm{N}_{\mathrm{CCAP}}$ during the late larval and early pupal periods. The pupal lethality normally associated with Kir2.1 expression in $\mathrm{N}_{\mathrm{CCAP}}$ appeared to be greatly enhanced at $31^{\circ} \mathrm{C}$. This constrained us to manipulations in which Kir2.1 expression was induced well after the time of puparium formation.

When Burs-Gal4::Gal80 ${ }^{\text {ts }}>$ UAS-Kir2.1 animals were grown through larval and early pupal development at $18^{\circ} \mathrm{C}$ and then transferred to $31^{\circ} \mathrm{C}$ at successively later times to induce Kir2.1 expression (and therefore the suppression of bursiconexpressing neurons), only those animals induced at the latest stages of development escaped the effects of suppression. Most animals raised at $18^{\circ} \mathrm{C}$ were found to eclose and expand their wings by day 9 after puparium formation (APF). Almost all ani- 
A

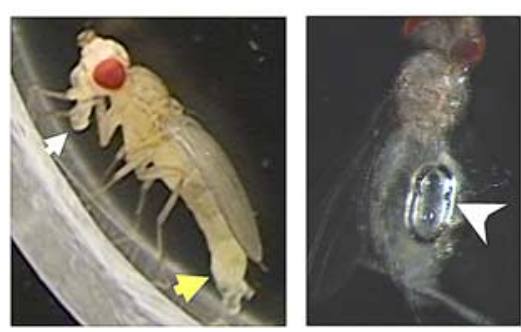

B
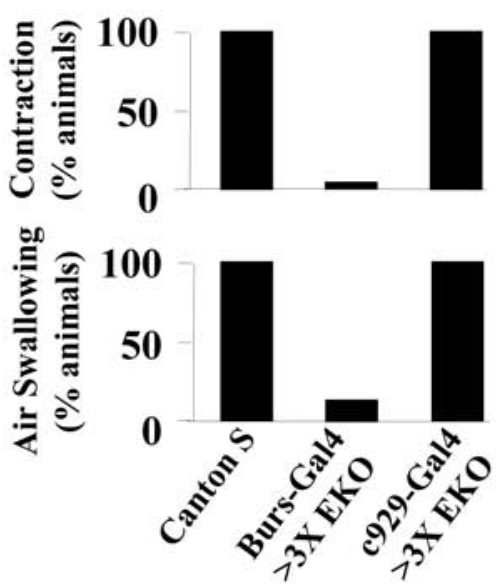

C

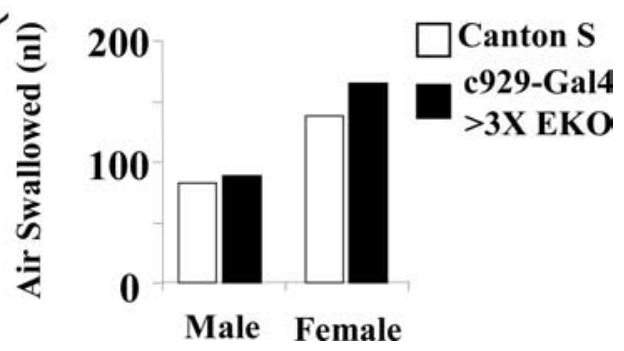

Figure 4. The $\mathrm{B}_{\mathrm{SEG}}$ and $\mathrm{B}_{\mathrm{AG}}$, but not the $\mathrm{B}_{\mathrm{AG}}$ alone, are required for two behaviors necessary for wing expansion: abdominal contraction and air swallowing. $\boldsymbol{A}$, Wild-type flies execute two behaviors during wing expansion: abdominal contraction (left) consisting of elongation and downward flexion of the abdomen (yellow arrow), and air swallowing, which requires an erect proboscis (white arrow) and results in accumulation of air in the gut (right, white arrowhead). $\boldsymbol{B}$, Bar graphs showing the frequency of abdominal contraction (top) and air swallowing (bottom) in (anton $S$ control, Burs-Gal $4>3 \times$ UAS-EKO, and $929-G a 14>3 \times$ UAS-EKO animals, as indicated. Burs-Gal 4 drives expression of the EKO suppressor channel in both the $B_{S E G}$ and $B_{A G}$ whereas (929-Gal4 drives its expression only in the $B_{A G}$. $C$, Bar graph showing that 0929 Gal4>UAS-3X-EKO males and females (black bars) swallow similar amounts of air as Canton $S$ control animals (white bars).

mals in which bursicon-expressing neurons were suppressed by transfer to $31^{\circ} \mathrm{C}$ between days 5-7 APF had unexpanded wings. Even transfer on day $8 \mathrm{APF}$, when the animals are late-stage pharate adults and Burs-Gal4 is expected to drive UAS-Kir2.1 expression only in bursicon-expressing neurons (Zhao et al., 2008), resulted in substantial numbers of animals with unexpanded or partially expanded phenotypes. This excludes the possibility that developmental suppression of $\mathrm{N}_{\mathrm{CCAP}}$ causes the wing expansion deficits observed with UAS-Kir2.1 and demonstrates that suppression typically acts at or after day 8 APF to impair the wing expansion process. Indeed, because neuronal suppression is the outcome of multiple slow steps (including the derepression of Gal4, the induction of Kir2.1 gene expression, and deployment of
Kir2.1 protein to the membrane at sites that will block excitability), suppression of $\mathrm{N}_{\text {Burs }}$ is likely to be complete only well after the temperature shift at the beginning of day 8 APF and may coincide approximately with the time of eclosion and wing expansion.

The substantial pupal lethality observed in Burs-Gal4::Gal80 ${ }^{\text {ts }}>$ UAS-Kir2. 1 animals at $31^{\circ} \mathrm{C}$ prevented us from examining the effects of reduced $\mathrm{N}_{\text {Burs }}$ excitability during development with Kir2.1, but we were able to address this issue using animals expressing $1 \times$ UASEKO. To do so, we took advantage of an intrinsic temperature sensitivity in the action of the EKO channel discovered in the course of experiments with the CCAP-Gal4 driver. These experiments revealed that the efficacy of UAS-EKO expression was inversely related to the temperature at which it was expressed (supplemental Fig. S2, available at www.jneurosci.org as supplemental material). Flies expressing a single copy of UAS-EKO under the control of CCAP-Gal4 and raised at $18^{\circ} \mathrm{C}$ uniformly failed to expand their wings, whereas flies of the same genotype raised at $31^{\circ} \mathrm{C}$ expanded their wings normally. The same pattern of temperature sensitivity was observed in animals expressing two and three copies of UAS-EKO (supplemental Fig. S2A, available at www.jneurosci.org as supplemental material).

These results were quite surprising, given that Gal4 activity is known to increase with temperature, and animals grown at $18^{\circ} \mathrm{C}$ typically show reduced levels of UAS-transgene expression than animals grown at higher temperatures. Indeed, we observed lower levels of fluorescence of a UAS-EGFP reporter transgene expressed in $\mathrm{N}_{\mathrm{CCAP}}$ in animals grown at $18^{\circ} \mathrm{C}$ relative to those grown at $31^{\circ} \mathrm{C}$ [supplemental Fig. S2 $B$ (bottom), available at www.jneurosci.org as supplemental material]. In contrast, the intrinsic GFP fluorescence of UAS-EKO increased at the lower temperature. The standing levels of the channel protein are thus higher at $18^{\circ} \mathrm{C}$, consistent with the temperature sensitivity of the wing expansion phenotypes. Although the intrinsic temperature sensitivity of UAS-EKO precluded its use with Gal $80^{\text {ts }}$, we were able to exploit this property to directly analyze the developmental effects of suppressing $\mathrm{N}_{\text {Burs }}$ with the EKO channel.

As shown in Figure $3 B$, expression of a single copy of EKO under the control of Burs-Gal4 yields wing expansion deficits at approximately fivefold higher frequency in animals raised at $18^{\circ} \mathrm{C}$ (at which EKO efficacy is high) compared with those raised at $31^{\circ} \mathrm{C}$ (at which EKO efficacy is low). While a fraction of animals raised at $18^{\circ} \mathrm{C}$ and then shifted to $31^{\circ} \mathrm{C}$ from 5 to $6 \mathrm{~d}$ APF show wing expansion deficits, the majority expand their wings normally, indicating that the effects of strong suppression at $18^{\circ} \mathrm{C}$ are reversed by the temperature shift during these stages of development. This argues strongly that suppression of excitability during the developmental period when Burs-Gal4 drives expression broadly in $\mathrm{N}_{\mathrm{CCAP}}$ has little to no effect on wing expansion. Only animals moved to $31^{\circ} \mathrm{C}$ on days 7-8 APF, showed strong effects of EKO-mediated suppression, indicating that suppression blocks wing expansion by acting on a process late in development. Because the time course with which EKO efficacy declines depends on factors such as channel turnover and gene expression rates at the different temperatures, which are not known, it is not possible to resolve the exact timing of that process, but as with UAS-Kir2.1, our results are consistent with UAS-EKO directly suppressing bursicon release after eclosion.

Suppression of all bursicon-expressing neurons, but not the $B_{A G}$ alone, inhibits wing expansion behaviors

Our results show that suppression of $\mathrm{N}_{\text {Burs }}$ with $3 \times$ UAS-EKO blocks bursicon release into the hemolymph. However, it is un- 

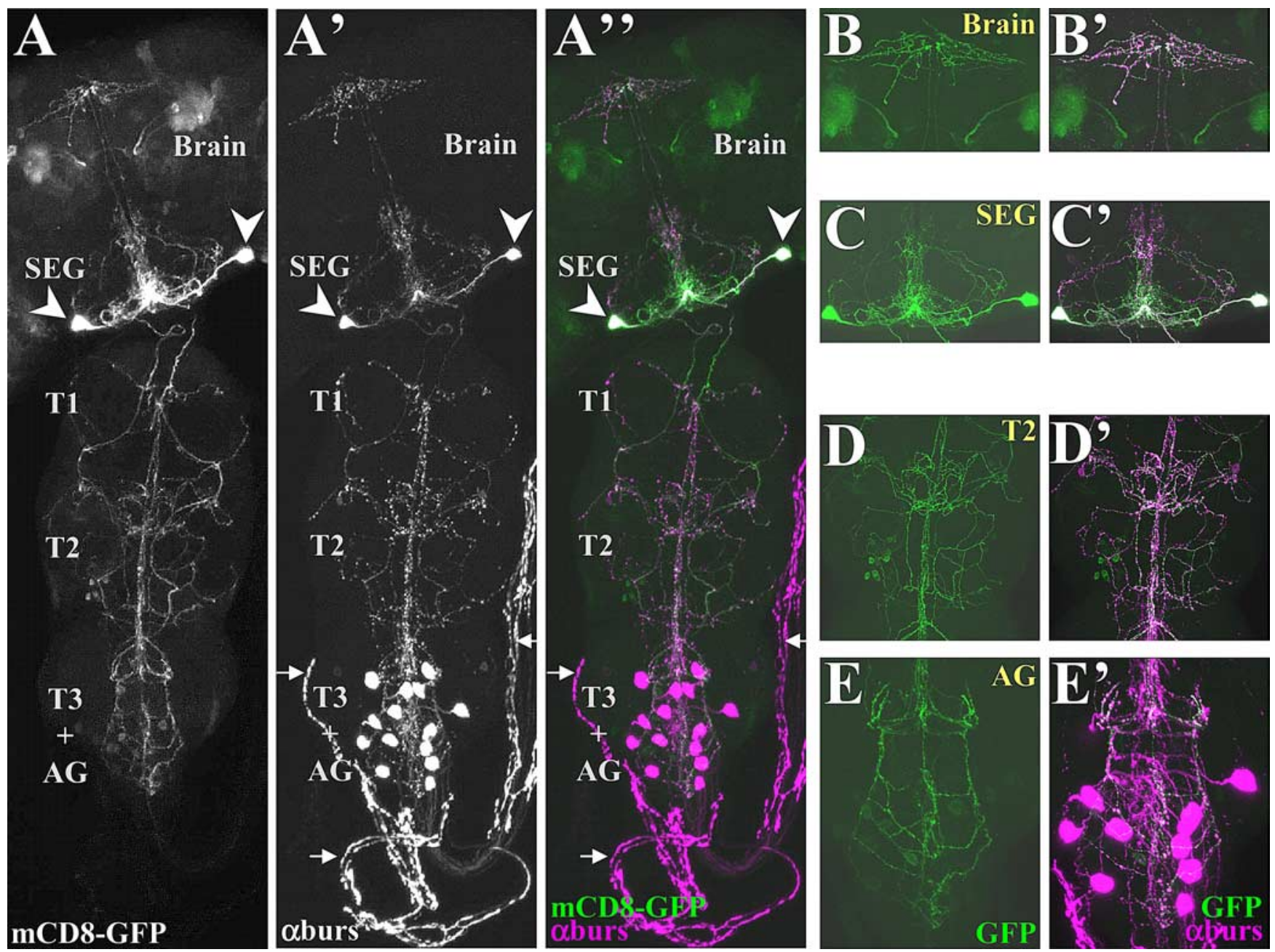

Figure 5. The bursicon-expressing neurons of the subesophageal ganglion $\left(B_{S E G}\right)$ project throughout the CNS. Confocal micrographs of a pharate adult nervous system in which both $B_{S E G}$ neurons have been labeled with mCD8-GFP (green) using the Flp-out system and the Burs-Gal4 driver. The preparation was double labeled with anti-burs antibody (magenta) to reveal the distribution of bursicon. $\boldsymbol{A}-\boldsymbol{A}^{\prime \prime}$, mCD8-GFP labeling $(\boldsymbol{A})$ and anti-burs immunostaining $\left(\boldsymbol{A}^{\prime}\right)$ overlap extensively in the (NS as seen in the merged image $\left(\boldsymbol{A}^{\prime \prime}\right)$. Arrows indicate the abdominal nerves, which lack a GFP (green) signal. Arrowheads, Somata of the $B_{\mathrm{SEG}} \cdot \boldsymbol{B}-\boldsymbol{E}^{\prime}$, Higher-magnification images of $B_{\mathrm{SEG}}$ processes in selected regions of the nervous system shown in $\boldsymbol{A}$. $\boldsymbol{B}-\boldsymbol{E}$, mCD8-GFP labeling (green) and overlapping anti-burs immunostaining $\left(\boldsymbol{B}^{\prime}-\boldsymbol{E}^{\prime}\right)$ in brain $\left(\boldsymbol{B}, \boldsymbol{B}^{\prime}\right)$, subesophageal ganglion $\left(\boldsymbol{C}, \boldsymbol{C}^{\prime}\right)$, second thoracic ganglion $\left(\boldsymbol{D}, \boldsymbol{D}^{\prime}\right)$, and abdominal ganglion $\left(\boldsymbol{E}, \boldsymbol{E}^{\prime}\right)$. Images in $\boldsymbol{A}-\boldsymbol{A}^{\prime \prime}$ are volume-rendered $z$-stacks acquired with a $20 \times$ objective representing the entire nervous system. $\boldsymbol{B}-\boldsymbol{E}^{\prime}$ represent limited image planes through the nervous system acquired with a $60 \times$ objective.

likely that the blood-borne hormone mediates bursicon's behavioral effects. As has been shown previously, injection of bursiconcontaining blood into newly emerged blowflies fails to induce air swallowing, although it does induce premature tanning (Cottrell, 1962a). It is possible, however, that the $B_{A G}$, which are the source of bursicon released into the hemolymph, also secrete the hormone within the CNS. To determine whether the $B_{A G}$ are required for the central effects of bursicon, we analyzed the behavior of flies expressing $3 \times$ UAS-EKO either in the $\mathrm{B}_{\mathrm{AG}}$, using the c929-Gal4 driver, or in both the $\mathrm{B}_{\mathrm{AG}}$ and $\mathrm{B}_{\mathrm{SEG}}$, using the BursGal4 driver (Fig. 4).

Posteclosion behavior divides into two distinct phases: perch selection, during which the fly selects a place to settle, and wing expansion, during which the fly ingests air and tonically contracts its abdomen to expand its wings (Fig. 4A). Although c929Gal4 $>3 \times$ UAS-EKO flies fail to expand their wings, they consistently display a period of sustained abdominal contraction characteristic of the expansional phase when observed after eclosion (Fig. $4 B$, top). Interestingly, this behavior differed slightly from that of Canton $S$ controls in many animals, with the abdomen elongated and constricted, but not necessarily flexed. The duration of contraction, however, was on average indistinguishable from that of control animals $(18 \pm 2.5 \mathrm{~min}$ vs $17 \pm 2.0 \mathrm{~min}$, respectively; $n=10$ in both cases). To confirm that the c929Gal4 $>3 \times$ UAS-EKO flies also were ingesting air, we killed animals immediately after the cessation of abdominal contraction and measured the volume of air in the gut (see Fig. $4 A$, right). All male and female c929-Gal4 $>3 \times$ UAS-EKO flies were found to swallow air (Fig. $4 B$, bottom) in amounts similar to that of Canton $\mathrm{S}$ controls (Fig. 4C). Animals in which the $\mathrm{B}_{\mathrm{AG}}$ were suppressed thus displayed behavior that was in almost all respects normal.

In contrast, only $4 \%$ of flies expressing $3 \times$ UAS-EKO under the control of the Burs-Gal4 driver displayed sustained abdominal contraction (Fig. 4 B, top), and 14\% swallowed air (Fig. $4 B$, bottom). Some flies contracted their abdomens for short intervals, as was also the case for wild-type flies before the period of sustained contraction (data not shown), but contraction never persisted for more than 2 min. Interestingly, all of the animals observed to swallow air (six of 43 total) were female (data not 


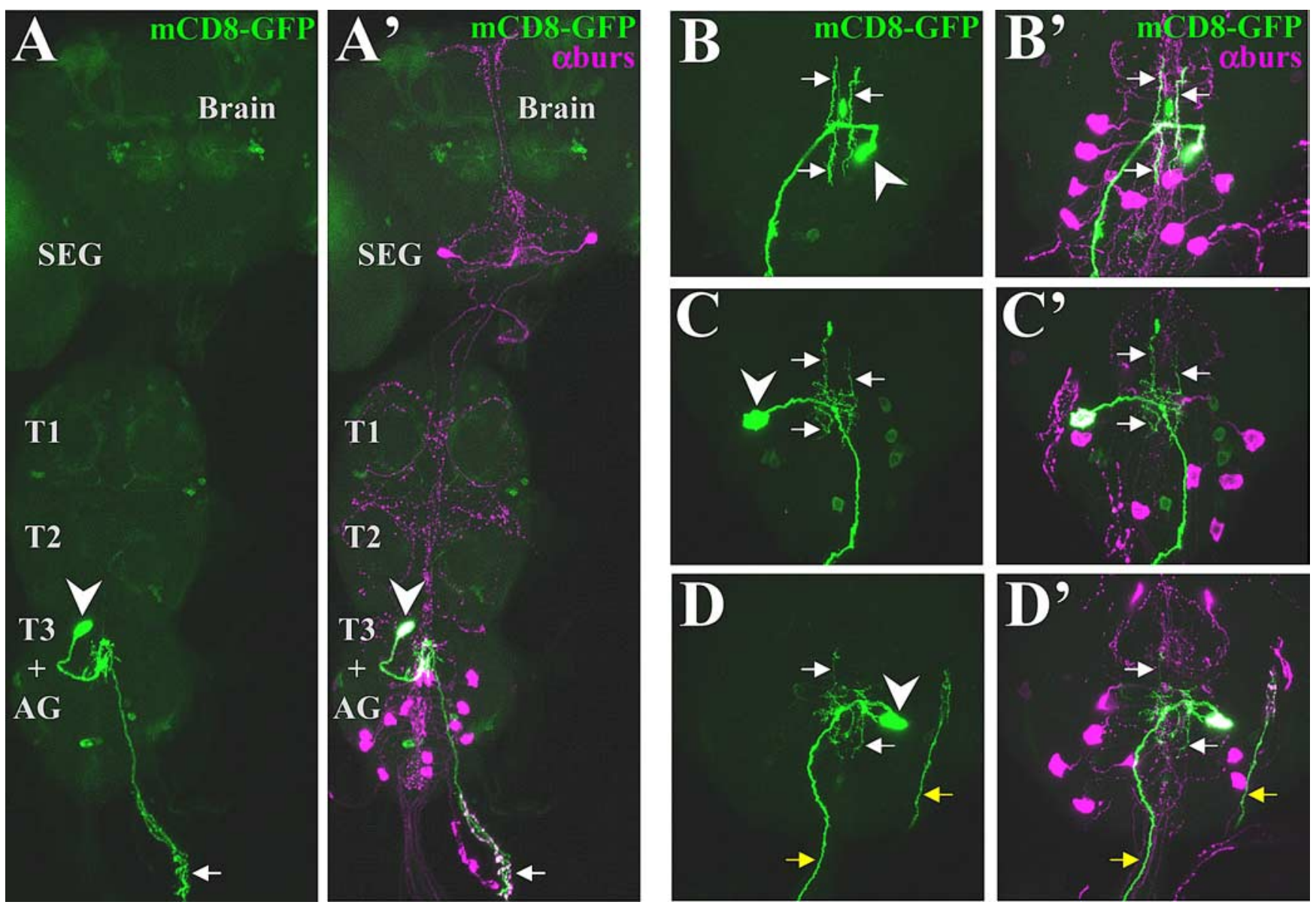

Figure 6. The bursicon-expressing neurons of the abdominal ganglion $\left(B_{A G}\right)$ project across the midline and exit posteriorly through abdominal nerves. $A, A^{\prime}$, The nervous system of a pharate adult in which a single $B_{A G}$ neuron was labeled with mCD8-GFP (green) using the Flp-out system and the Burs-Gal4 driver. In $A^{\prime}$, the preparation was double labeled with anti-burs antibodies (magenta) to reveal the distribution of bursicon. Arrowheads, Somata. Arrows, Process in an abdominal nerve. $\boldsymbol{B}-\boldsymbol{D}$, High-magnification images of the abdominal ganglion from three different adults in which a single $B_{A G}$ (arrowhead) was labeled with $\mathrm{mCD}$-GFP (green). $\boldsymbol{B}^{\prime}-\boldsymbol{D}^{\prime}$, Corresponding images showing the distribution of bursicon after double labeling with anti-burs antibodies (magenta). In each case, the axon ramifies at the midline (white arrows) before crossing and exiting the abdominal ganglion through a posterior nerve. Yellow arrows in $\boldsymbol{D}$ and $\boldsymbol{D}^{\prime}$ show the labeled axon in a nerve bundle that has wrapped back over the ganglion after excision. Confocal images in $\boldsymbol{A}$ and $\boldsymbol{A}^{\prime}$ were acquired with a $20 \times$ objective, and those in $\boldsymbol{B}-\boldsymbol{D}^{\prime}$ were acquired with a $60 \times$ objective.

shown). This suggests that males are more sensitive to the effects of $\mathrm{N}_{\text {Burs }}$ suppression, an observation consistent with the fact that weak suppression in $\mathrm{N}_{\text {Burs }}$ with $1 \times \mathrm{EKO}$ is four times more likely to result in partial wing deficits in male flies than in females (data not shown). The finding that some flies swallowed air and displayed short bouts of abdominal contraction also is consistent with the observation that a small fraction of these animals partially expanded their wings when allowed to eclose unperturbed (Fig. 2A).

The fact that expansional behaviors are largely absent in animals in which both the $\mathrm{B}_{\mathrm{SEG}}$ and $\mathrm{B}_{\mathrm{AG}}$ are suppressed (i.e., BursGal4 $>3 \times$ UAS-EKO animals), but present in those in which only the $\mathrm{B}_{\mathrm{AG}}$ are suppressed (i.e., $\mathrm{c} 929-\mathrm{Gal} 4>3 \times \mathrm{UAS}-\mathrm{EKO}$ animals), demonstrates that the $\mathrm{B}_{\mathrm{SEG}}$ are necessary for the execution of these behaviors. Together with genetic data demonstrating that bursicon signaling is required for expansional behaviors (Baker and Truman, 2002), our results imply that bursicon derived specifically from the $\mathrm{B}_{\mathrm{SEG}}$ governs the motor patterns underlying wing expansion.

Bursicon-containing fibers of the $B_{\mathrm{SEG}}$, but not the $\mathrm{B}_{\mathrm{AG}}$, project to all major regions of the CNS

As illustrated by the anti-burs immunostaining shown in Figure $1 F$, the CNS of the pharate adult fly contains profuse bursicon- immunoreactive (i.e., bursicon-IR) fibers in the brain, as well as in the subesophageal, thoracic, and abdominal ganglia. Most of these fibers have pronounced varicosities characteristic of release sites, suggesting that the hormone is being secreted into the CNS. In addition, the proximal portions of the lateral abdominal nerves (Fig. 1F, arrow) are densely laden with bursiconcontaining varicosities, which have been shown to be neurohemal sites of release (Zhao et al., 2008). Because bursicon released into the hemolymph derives from the $\mathrm{B}_{\mathrm{AG}}$, the fibers in the $\mathrm{ab}$ dominal nerves must derive from these neurons, a conclusion consistent with the anatomy of the homologous neurons in other insects (Taghert and Truman, 1982; Honegger et al., 2002; Dai et al., 2008). We reasoned therefore that the $B_{S E G}$ were likely to give rise to the central bursicon-IR projections, a hypothesis consistent with their role in regulating behavioral changes.

To test this hypothesis, we used the "Flp-out" mCD8-GFP system (Wong et al., 2002) in conjunction with the Burs-Gal4 driver to fluorescently label small numbers of bursiconexpressing neurons and their neurites. Preparations in which only $\mathrm{B}_{\mathrm{SEG}}$ neurons (Fig. $5 \mathrm{~A}$ ) were labeled consistently showed GFP-labeled processes that ramified throughout the CNS. These processes were in register with the bursicon-IR fibers visualized by anti-burs immunostaining (Fig. 5 $A^{\prime}$ ), with GFP-labeled 
A

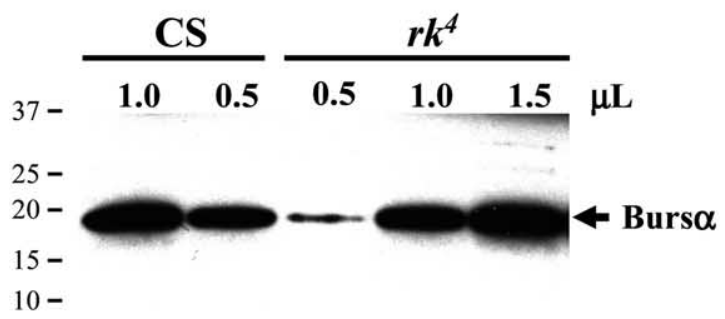

B
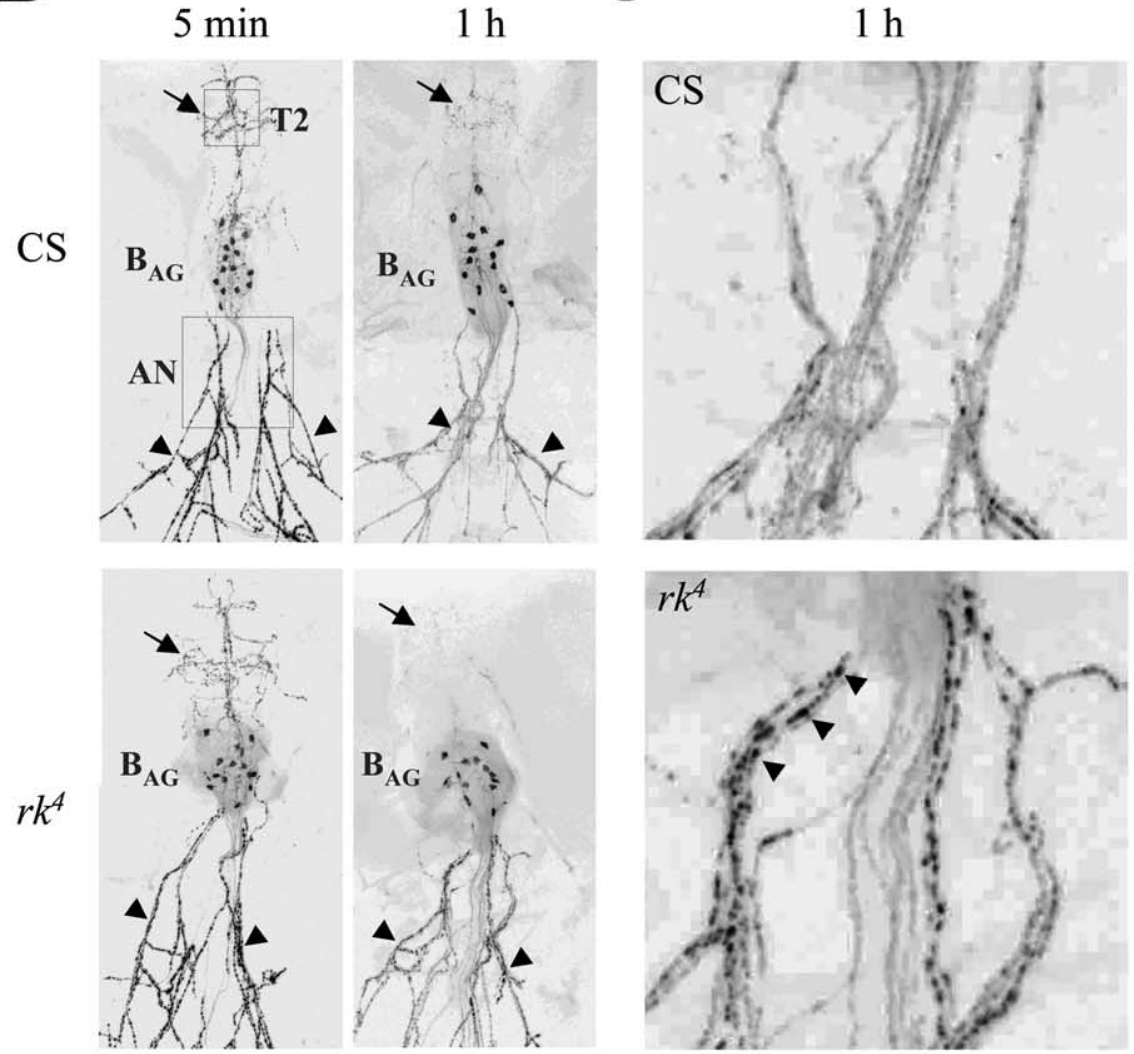

D

B $_{\text {SEG }}$
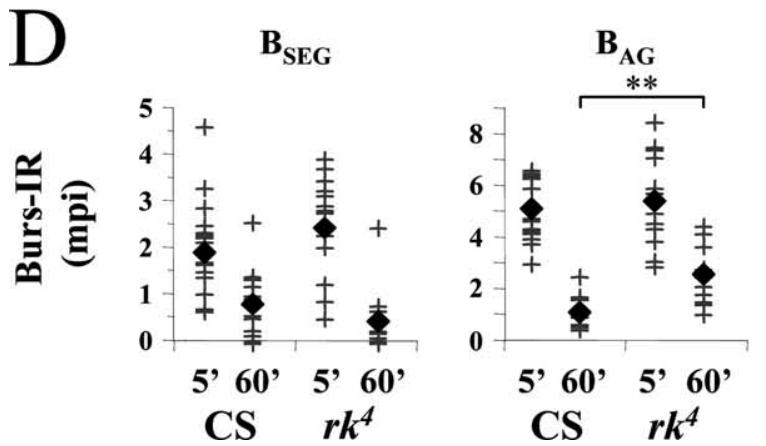

口

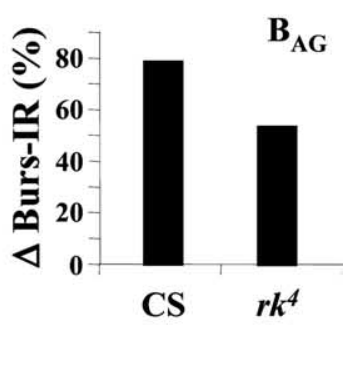

Figure 7. Bursicon secretion from the $\mathrm{B}_{\mathrm{AG}}$, but not the $\mathrm{B}_{\mathrm{SEG}}$, is impaired in $r k^{4}$ mutants. $\boldsymbol{A}$, Western blot showing the bursicon content of hemolymph extracted from either Canton $S$ control flies or $r k^{4}$ mutants within $1 \mathrm{~h}$ of eclosion. Samples containing the indicated volumes of pooled hemolymph, collected from at least 40 animals of each genotype, were loaded into each lane, and the blot was probed with anti-burs antibodies. The positions of selected molecular weight markers (in kDa) are shown. The bursicon $\alpha$-subunit (arrow, Burs $\alpha$ ) runs at $\sim 16 \mathrm{kDa}$. B , Confocal images of anti-bursicon immunostaining in whole mounts of adults filleted to reveal the ventral nervous system and the abdominal nerves. Nervous system preparations are from either Canton $S$ (CS) control animals or from $r k^{4}$ mutants, killed 5 min or 60 min after eclosion, as indicated. Dotted boxes in the 5 min, CS preparation indicate the size and location of the fields used to calculate the intensity of immunolabeling of central processes belonging to the $B_{S E G}\left(T 2\right.$; arrows) or peripheral processes belonging to the $B_{A G}$ in the abdominal nerves (AN; arrowheads). The position of the $B_{A G}$ puncta often coinciding with sites of varicosities (Fig. 5 $A^{\prime \prime}$ ). Higher-magnification images confirmed the overlap of neurite labeling in the brain (Fig. $5 B, B^{\prime}$ ) and the subesophageal ganglion (Fig. $5 C, C^{\prime}$ ), and in the thoracic (Fig. 5D, $D^{\prime}$ ) and abdominal neuromeres (Fig. $5 E, E^{\prime}$ ). Interestingly, the $\mathrm{B}_{\mathrm{SEG}}$ processes in the abdominal ganglion ramified at the level of the $B_{A G}$ neurons, often branching laterally between neuromeres and also extensively along the midline, where the $\mathrm{B}_{\mathrm{AG}}$ axons arborized (see below). While both $\mathrm{B}_{\mathrm{SEG}}$ neurons were fortuitously labeled in the preparation shown in Figure 5, all other preparations that we generated using the Flp-out technique contained a single labeled neuron (supplemental Fig. S4, available at www.jneurosci.org as supplemental material). These preparations clearly demonstrated that each $B_{\text {SEG }}$ neuron sends its primary neurite toward the midline, where it ramifies, then crosses the midline and descends through the cervical connective into the ventral nerve cord. There it arborizes principally, but not exclusively, on the side contralateral to that of the cell body. The origin of the $\mathrm{B}_{\mathrm{SEG}}$ projection to the brain was more difficult to discern, and interestingly both ipsilateral and contralateral fibers from a single neuron could typically be seen [supplemental Fig. S $4 A, B$ (arrows), available at www.jneurosci.org as supplemental material].

\section{$\leftarrow$}

is also indicated. $C$, Higher resolution images of the abdominal nerve regions of the preparations shown in $\boldsymbol{B}$. Arrowheads indicate bursicon immunoreactive varicosities abundant in the abdominal nerves of animals $5 \mathrm{~min}$ after eclosion and also frequently found in the nerves of $r k^{4}$ animals 60 min after eclosion (bottom). Such varicosities are, however, rare in the nerves of control animals after $60 \mathrm{~min}$ (top), where bursicon is largely depleted. $\boldsymbol{D}$, Graphs showing the bursicon immunoreactivities (Burs-IR) associated with the $B_{S E G}$ fibers (left) or $B_{A G}$ fibers (right) in 13-18 preparations of the type shown in $\boldsymbol{B}$. Each cross represents the Burs-IR value determined for an individual preparation, measured as the mean pixel intensity (mpi, background-subtracted) of an area centered over the proximal abdominal nerves (for the $\mathrm{B}_{\mathrm{AG}}$ ) or the central $\mathrm{T} 2$ thoracic region (for the $B_{\mathrm{SEG}}$ ), as depicted in the top left panel in $\boldsymbol{B}$ (dotted areas). Filled diamonds represent the mean Burs-IR values for preparations of each indicated type. In all cases, the difference in mean Burs-IR values at $5 \mathrm{~min}$ and $60 \mathrm{~min}$ for like samples (i.e., samples representing same fiber type in animals of the same genotype) was determined to be highly significant by $t$ test, as noted in Results. In contrast, the difference in mean Burs-IR values measured for a given fiber type at a given time, but in animals of different genotype, was not statistically significant except for $B_{A G}$ measurements at 60 $\min$, as indicated by double asterisks $\left(p=2 \times 10^{-4}\right)$. $\boldsymbol{E}$, Bar graph depicts the change in mean Burs-IR measured for the $\mathrm{B}_{\mathrm{AG}}$ of $\mathrm{Canton} S(C S)$ control and $r k^{4}$ mutant animals between $5 \mathrm{~min}$ and $60 \mathrm{~min}$. 
The complex projection patterns of the $\mathrm{B}_{\mathrm{SEG}}$ contrast with the relatively simple patterns observed for the $\mathrm{B}_{\mathrm{AG}}$ neurons (Fig. $6 \mathrm{~A}-$ $D)$. None of the GFP-marked processes from 16 preparations in which single $\mathrm{B}_{\mathrm{AG}}$ neurons were labeled projected anteriorly out of the abdominal ganglion. Instead, the axon in all cases extended toward the midline, where it sent multiple short branches both anteriorly and posteriorly before continuing down the contralateral side and exiting the ganglion through an abdominal nerve (Fig. 6A, $A^{\prime}$ ). Within the $\mathrm{CNS}$, the $\mathrm{B}_{\mathrm{AG}}$ processes typically stained weakly with the anti-burs antibody (Fig. $\left.6 A^{\prime}-D^{\prime}\right)$ and contained few varicosities. Only when they entered the abdominal nerves did the bursicon immunoreactivity of many of these fibers become intense with dense, punctate labeling. The $\mathrm{B}_{\mathrm{AG}}$ neurons and their midline branches, however, were often in the vicinity of varicose processes (Fig. $6 A^{\prime}-D^{\prime}$ ), which presumably derive from the $\mathrm{B}_{\mathrm{SEG}}$ based on the arborization patterns of these neurons.

\section{Bursicon neuromodulation of hormone release: bursicon secretion from the $\mathrm{B}_{\mathrm{AG}}$ is attenuated in rickets mutants}

The extensive arborization of the $\mathrm{B}_{\mathrm{SEG}}$ processes suggests that these neurons have numerous targets within the CNS. Interestingly, the projection of the $\mathrm{B}_{\mathrm{SEG}}$ fibers into the abdominal ganglion, and their proximity to the $\mathrm{B}_{\mathrm{AG}}$, raises the possibility that the $\mathrm{B}_{\mathrm{SEG}}$ may communicate with these neurons, either directly or indirectly. In the simplest case, bursicon released by the $\mathrm{B}_{\mathrm{SEG}}$ could regulate bursicon secretion into the hemolymph by the $\mathrm{B}_{\mathrm{AG}}$. Consistent with this, Baker and Truman (2002) have shown that $r k^{4}$ mutants, which lack a functional bursicon receptor, may release variable amounts of the hormone after eclosion, as determined by bioassay. We reasoned that bursicon secretion from the $\mathrm{B}_{\mathrm{AG}}$ in $r k^{4}$ mutants might be disrupted by lesions in the bursicon signaling pathway downstream of the $\mathrm{B}_{\mathrm{SEG}}$. If this is so, bursicon release from the $B_{\mathrm{SEG}}$ in the mutants should be normal and release from the $\mathrm{B}_{\mathrm{AG}}$ aberrant.

To determine whether bursicon secretion from the $\mathrm{B}_{\mathrm{AG}}$ is impaired, we measured the levels of hormone present in the hemolymph of $r k^{4}$ mutants by Western blot $1 \mathrm{~h}$ after eclosion, a time at which bursicon is detected in a $0.5 \mu$ sample of hemolymph from control animals (Luan et al., 2006) (Fig. 7A). Bursicon is also detectable in $0.5 \mu \mathrm{l}$ samples of hemolymph of $r k^{4}$ mutants at this time, but at lower levels than in control animals. Since this highly amplified chemiluminescent signal was near the detection limit of our Western blotting method and not in the linear range, we probed sets of samples of varying volume from common pools of hemolymph collected from $>40$ animals of each genotype. This allowed us to estimate the relative levels of released bursicon in CS controls and $r k^{4}$ mutants. The results (Fig. 7A), which show that $1.0 \mu \mathrm{l}$ of hemolymph from $r k^{4}$ animals yields a signal of similar magnitude as $0.5 \mu \mathrm{l}$ of hemolymph from control animals, indicate an $\sim 50 \%$ reduction of bursicon release from the $\mathrm{B}_{\mathrm{AG}}$ in the mutants.

To better quantify the reduction in $\mathrm{B}_{\mathrm{AG}}$ bursicon secretion, and to analyze release from the $\mathrm{B}_{\mathrm{SEG}}$, we next measured the levels of bursicon immunoreactivity (Burs-IR) in the $\mathrm{B}_{\mathrm{AG}}$ and $\mathrm{B}_{\mathrm{SEG}}$ processes from animals killed either 5 or $60 \mathrm{~min}$ after eclosion. As previously shown by Zhao et al. (2008), bursicon is substantially depleted from the abdominal nerves in control animals $1 \mathrm{~h}$ after eclosion (Fig. $7 B, C$, top, arrowheads), as is the immunoreactivity in central fibers belonging to the $\mathrm{B}_{\mathrm{SEG}}$ (Fig. $7 B$, top, arrows). The Burs-IR of $\mathrm{B}_{\mathrm{SEG}}$ processes is also depleted in $r k^{4}$ mutants at this time (Fig. $7 B$, bottom, arrows), indicating that these neurons release their contents normally. In contrast, and consistent with our Western blot data, the Burs-IR of $\mathrm{B}_{\mathrm{AG}}$ processes in $r k^{4} \mathrm{mu}-$ tants is often not fully depleted $60 \mathrm{~min}$ after eclosion (Fig. $7 A, B$, bottom, arrowheads). Fibers with bursicon-immunoreactive varicosities that are characteristically found in the abdominal nerves of both control and mutant animals 5 min after eclosion (Fig. $7 B$, left) are frequently present in at least some nerves of most $r k^{4}$ mutants $1 \mathrm{~h}$ after eclosion (Fig. 7C, bottom, arrowheads), but rarely in nerves of Canton $S$ control animals (Fig. 7C, top).

Figure $7 D$ summarizes the immunostaining results from all preparations analyzed. As expected, the mean Burs-IR of the $B_{\text {SEG }}$ and $\mathrm{B}_{\mathrm{AG}}$ processes (Fig. $7 \mathrm{D}$, black diamonds) is significantly lower at $60 \mathrm{~min}$ than it is at $5 \mathrm{~min}$ in both control animals and $r k^{4}$ mutants ( $p<10^{-3}$ by $t$ test), indicative of bursicon depletion. For the $\mathrm{B}_{\mathrm{SEG}}$ processes, the average decline in Burs-IR is greater for $r k^{4}$ mutants than it is for control animals (Fig. 7D, left), suggesting that bursicon release from the $\mathrm{B}_{\mathrm{SEG}}$ may be elevated in the mutants. However, pairwise comparison of the $r k^{4}$ and Canton $\mathrm{S}$ $\mathrm{B}_{\mathrm{SEG}}$ Burs-IR values at $5 \mathrm{~min}$ and at $60 \mathrm{~min}$ fails to support this conclusion, as there is no statistically significant difference in their distributions at either time point. In contrast, a similar pairwise comparison of the $\mathrm{B}_{\mathrm{AG}}$ Burs-IR values shows that bursicon levels are indistinguishable in control and mutant animals at 5 min, but are significantly elevated at $1 \mathrm{~h}$ in $r k^{4}$ mutants (Fig. 7D, double asterisks). On average, over twice as much bursicon remains in the $\mathrm{B}_{\mathrm{AG}}$ fibers of $r k^{4}$ mutants after $1 \mathrm{~h}$ as remains in the corresponding fibers of Canton $S$ controls (Fig. $7 D$, right). This results in an estimated 30\% decrease in bursicon release in $r k^{4}$ mutants compared with control animals (Fig. 7E), similar to the estimate derived above from our Western blot data. It is worth noting, however, that despite the significant difference in their distributions, the $\mathrm{B}_{\mathrm{AG}}$ Burs-IR values for $r k^{4}$ mutants at 5 and 60 min overlap considerably (Fig. $7 D$, right), indicating that the amounts of hormone released into the hemolymph by individual $r k^{4}$ animals may be quite variable. This is consistent with the earlier observations of Baker and Truman (2002). Together, our results indicate that bursicon secretion from the $\mathrm{B}_{\mathrm{AG}}$ is impaired in $r k^{4}$ mutants, while release from the $\mathrm{B}_{\mathrm{SEG}}$ is normal.

\section{Bursicon neuromodulation of apoptosis: death of $B_{A G}$ neurons is delayed in rickets mutants}

One of the somatic actions of humorally transported bursicon is to induce apoptosis of the wing epidermis (Kimura et al., 2004). Certain central neurons also undergo programmed cell death after wing expansion (Kimura and Truman, 1990), including a group of CCAP-expressing neurons in the ventral ganglia that includes the $\mathrm{B}_{\mathrm{AG}}$ (Draizen et al., 1999). The latter neurons have been shown to undergo DNA condensation and fragmentation within $6 \mathrm{~h}$ of eclosion and to die within $14 \mathrm{~h}$. Because our data suggest that the $\mathrm{B}_{\mathrm{AG}}$ may be bursicon targets, we asked whether bursicon signaling was required for their demise.

To determine whether the $\mathrm{B}_{\mathrm{AG}}$ initiate apoptosis normally in $r k^{4}$ mutants, we performed TUNEL on nervous system preparations taken from both $r k^{4}$ and Canton S control animals killed $6 \mathrm{~h}$ after eclosion. As expected, the nuclei of most $\mathrm{B}_{\mathrm{AG}}$ neurons in control animals $(96 \%, n=140)$ showed staining indicative of DNA fragmentation (Fig. $8 \mathrm{~A}$, left). In contrast, very few of the $\mathrm{B}_{\mathrm{AG}}$ nuclei in $r k^{4}$ mutants $(12 \%, n=96)$ were similarly labeled (Fig. $8 \mathrm{~A}$, right, arrow). Apoptosis of the $\mathrm{B}_{\mathrm{AG}}$ is thus clearly not initiated on time in $r k^{4}$ animals. However, the presence of apoptotic profiles in some $B_{A G}$ neurons in the mutants suggested that cell death might simply be delayed.

To monitor the progression of $\mathrm{B}_{\mathrm{AG}}$ cell death in both $r k^{4} \mathrm{mu}-$ tants and control animals, we stained CNS whole-mount prepa- 
A
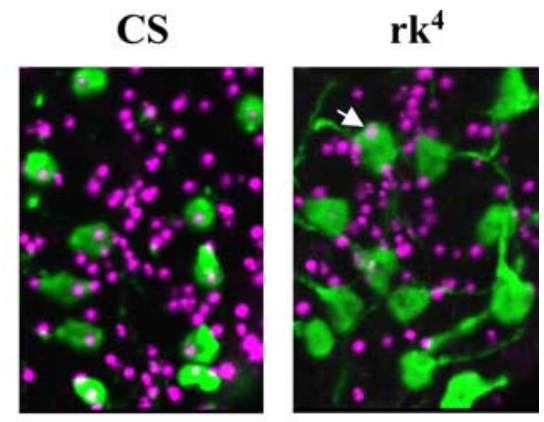

B

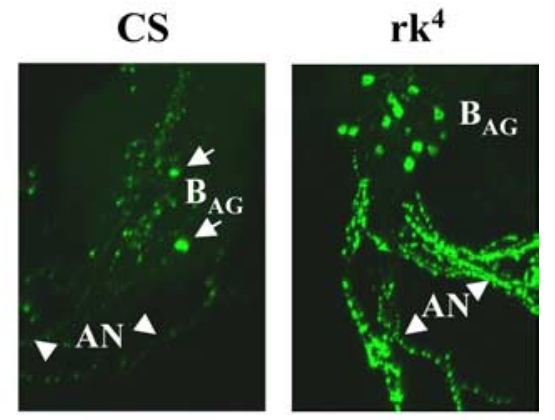

C

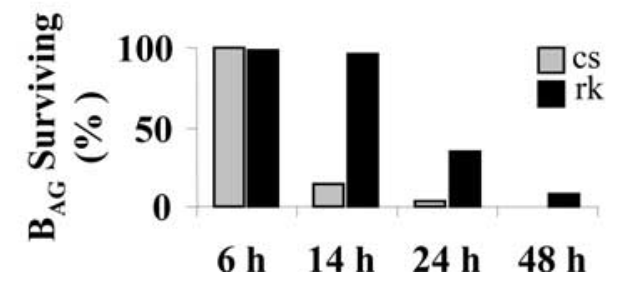

Figure 8. Cell death of the $\mathrm{B}_{\mathrm{AG}}$ is delayed in $r k^{4}$ mutants. $A$, Apoptosis is initiated within $6 \mathrm{~h}$ of eclosion in the $B_{A G}$ of Canton $S$ control animals (CS, left) but not in those of rickets ${ }^{4}$ mutants $\left(r k^{4}\right.$, right). Each image is a composite of five merged confocal z-sections showing most of the $B_{A G}$ (green) from a representative animal, visualized by anti-burs immunostaining. TUNEL (magenta), which indicates DNA fragmentation, can be seen in the nuclei of all $11 B_{A G}$ from the control animal (left), but only one of $12 B_{A G}$ nuclei (arrow) is labeled in the nervous system preparation from a $r k^{4}$ animal (right). TUNEL-labeled nuclei of many neurons other than the $B_{A G}$ are also visible, consistent with a broader pattern of posteclosion apoptosis (see Results). $\boldsymbol{B}$, Volume rendered confocal micrographs of the abdominal ganglion and abdominal nerves (AN, arrowheads) from Canton $S$ control (CS, left) and rickets ${ }^{4}\left(r k^{4}\right.$, right) animals immunostained with anti-burs antibody. All $B_{A G}$ are present in the abdominal ganglion of the $r k^{4}$ mutant, while only two survive in the abdominal ganglion of the control animal (arrows). Substantial bursicon immunoreactivity is associated with the processes of surviving $B_{A G}$ in the abdominal nerves of the $r k^{4}$ mutants. $C$, Bar graph showing the percentage of $B_{A G}$ neurons still present in animals at the indicated times after eclosion. CS, Canton $S$ control animals; $r k^{4}$, rickets mutants. Cell counts were averaged from at least six preparations for each genotype and time point.

rations with anti-burs antibodies and counted the immunopositive neurons in the abdominal ganglia from animals killed 6, 14, 24, and $48 \mathrm{~h}$ after eclosion. Consistent with previous results (Draizen et al., 1999), we found that few immunopositive $B_{\mathrm{AG}}$ neurons remained in control animals $14 \mathrm{~h}$ after eclosion [Fig. $8 \mathrm{~B}$ (left, arrows), C]. In contrast, $95 \%$ of the $\mathrm{B}_{\mathrm{AG}}$ in $r k^{4}$ animals were still present at this time [Fig. $8 B$ (right), $C$ ]. Consistent with this differential pattern of cell survival, the abdominal nerves in $r k^{4}$ animals also retained considerable immunoreactivity compared with those of controls, which were largely depleted of bursicon (Fig. 8 B, compare left and right panels, arrowheads). At $24 \mathrm{~h}$ after eclosion, when only $2 \%$ of $\mathrm{B}_{\mathrm{AG}}$ neurons were detectable in controls, over one-third of these neurons were evident in $r k^{4}$ animals, and $>8 \%$ were still immunopositive in 2 -d-old $r k^{4}$ adults (Fig.
$8 C)$. These data indicate that death of the $\mathrm{B}_{\mathrm{AG}}$ is significantly slowed in animals in which normal bursicon signaling is disrupted.

\section{Discussion}

The study of insect ecdysis has provided a productive model for investigating the hormonal control of behavior. Bursicon acts directly after adult ecdysis in Drosophila to initiate the somatic processes and motor programs underlying wing expansion and to induce rapid cuticle tanning. In Drosophila, the architecture of bursicon release differs from that of the other principal hormones that regulate ecdysis-related behaviors in that it is secreted not from a homogenous group of cells subject to common regulatory control, but instead from two distinct subsets of neurons. The work presented here demonstrates that this anatomical partition mirrors functional differences between the two subsets of bursicon-expressing neurons. One group (the $\mathrm{B}_{\mathrm{AG}}$ ) secretes bursicon into the hemolymph, and the other (the $\mathrm{B}_{\mathrm{SEG}}$ ) releases it widely in the nervous system to initiate the motor programs that underlie wing expansion. Our observation that secretion of bursicon from the $\mathrm{B}_{\mathrm{AG}}$ is impaired in rickets mutants is consistent with a model in which bursicon secreted by the $\mathrm{B}_{\mathrm{SEG}}$ also modulates release from the $\mathrm{B}_{\mathrm{AG}}$. Our results thus provide a framework for understanding how the somatic actions of bursicon are coordinated with its effects on behavior. In addition, our finding that apoptosis of the $\mathrm{B}_{\mathrm{AG}}$ is delayed in rickets mutants exposes a novel neuromodulatory function for bursicon.

\section{The $\mathrm{B}_{\mathrm{AG}}$ govern neurohemal release}

That bursicon is released into the blood from neurons in the abdominal ganglia has long been known from work in several insects (Fraenkel and Hsiao, 1965; Mills et al., 1965; Truman, 1973) and was recently confirmed in Drosophila (Luan et al., 2006; Zhao et al., 2008). Segmentally represented pairs of cells homologous to the $\mathrm{B}_{\mathrm{AG}}$ also have been identified in abdominal neuromeres of the hawkmoth Manduca sexta and other insects, in which the anatomy of their projections closely resembles that described here (Taghert and Truman, 1982; Dai et al., 2008). The large amount of bursicon expressed in the axons of these neurons after they leave the CNS (see Fig. 6 $A^{\prime}$ ) supports the conclusion that they are responsible for most, if not all, of the hormone released into the blood. Once in the blood, the hormone has been shown not only to activate tanning, in part by upregulating epidermal tyrosine hydroxylase (Davis et al., 2007), but also to alter the physiology of the wing. Early evidence that bursicon plasticizes the cuticle of the wing before expansion in Manduca (Reynolds, 1977) has been confirmed recently using recombinant hormone (Dai et al., 2008), and genetic evidence from Drosophila indicates that bursicon mediates apoptosis of the wing epidermis after expansion as a prerequisite for the fusion of the two cuticular panels (Kimura et al., 2004). Anatomical and functional evidence thus supports a humoral role for bursicon released from the $\mathrm{B}_{\mathrm{AG}}$, with these neurons mediating changes in the wing cuticle that support expansion. This conclusion is consistent with the projection pattern of these neurons described here, as well as with the observation that selective suppression of the $\mathrm{B}_{\mathrm{AG}}$ (i.e., in c929-Gal4>3 $\times$ UAS-EKO animals) blocks wing expansion, even though this manipulation leaves expansional behaviors intact. Presumably the inhibition of bursicon release into the hemolymph in these animals prevents the changes in cuticle plasticity required to render the wings pliable. 


\section{The $\mathrm{B}_{\mathrm{SEG}}$ secrete bursicon centrally and are required for behavior}

The data we present here demonstrate that the Drosophila $\mathrm{B}_{\mathrm{SEG}}$, and not the $\mathrm{B}_{\mathrm{AG}}$, are required for wing expansion behaviors. The broad projection pattern of these neurons in the CNS is consistent with their targeting multiple motor systems to activate both air swallowing and abdominal contraction, although their precise targets remain to be determined. Work from Manduca suggests that the circuitry underlying wing expansion may be similar in this insect. Wing expansion in Manduca is known to require intact descending connections from the subesophageal ganglion (Truman and Endo, 1974), and hawkmoths have $\mathrm{B}_{\mathrm{SEG}}$ homologues, which localize to the labial neuromere of the subesophageal ganglion and send descending projections to all posterior ganglia (Dai et al., 2008). Further work will be required to determine the generality of this functional neuronal architecture in insects. Blowflies appear to represent an exception insofar as bursicon has been reported absent in the subesophageal ganglion in these animals (Fraenkel and Hsiao, 1965). Instead, bursicon is synthesized by neurosecretory cells of the brain, which have been implicated in wing expansion behaviors (Fraenkel and Hsiao, 1965). Reexamination of these conclusions, which predate the availability of antibodies to the hormone and were based on tanning bioactivity assays, should help clarify the extent to which bursicon-expressing neurons in the subesophageal ganglion are likely to play a common role in insects.

\section{Neuromodulation of hormone secretion by bursicon}

The widespread release of bursicon in the nervous system, evidenced by the depletion of anti-burs immunostaining from the $\mathrm{B}_{\mathrm{SEG}}$ fibers after eclosion, suggests that centrally secreted bursicon has multiple functions. Our discovery that rickets mutants, which lack a functional bursicon receptor, exhibit diminished humoral release of bursicon from the $\mathrm{B}_{\mathrm{AG}}$ points to a role beyond behavioral control. It remains to be shown that bursicon acts as a centrally derived paracrine factor in potentiating its release from the $\mathrm{B}_{\mathrm{AG}}$, but there is reason to believe that the $\mathrm{B}_{\mathrm{AG}}$ may be direct targets of bursicon. Bursicon signaling is mediated by the cAMP pathway (Luo et al., 2005; Mendive et al., 2005), and we showed previously that suppression of protein kinase A (PKA), one of the principal effectors of this pathway, decreases the release of bursicon (Luan et al., 2006). Although this reduction was not sufficient to disrupt wing expansion and tanning, more recent experiments demonstrate that greater suppression of PKA reduces bursicon release sufficiently to cause highly penetrant wing expansion deficits (F. Diao and B. White, unpublished observations). This is consistent with the observations of Zhao et al. (2008), who similarly reported that overexpression of a cAMP phosphodiesterase (UAS-dunce) in the $\mathrm{B}_{\mathrm{AG}}$ using c929-Gal4 results in wing expansion deficits in many flies when two copies of UAS-dunce are expressed.

The conclusion that centrally secreted bursicon participates in regulating its release as a hormone from the $\mathrm{B}_{\mathrm{AG}}$ is interesting in light of the long-standing observation that bursicon release into the hemolymph requires descending signals from the head. Decapitation or neck ligation of both blowflies (Cottrell, 1962a; Fraenkel and Hsiao, 1962) and Drosophila (Kimura and Truman, 1990; Baker and Truman, 2002) soon after eclosion prevents tanning and wing expansion. Incisions that sever the ventral nerves in the neck of blowflies have also been reported to prevent tanning, but not air swallowing (Fraenkel and Hsiao, 1965), suggesting that air swallowing, like tanning, is initiated by a signal that originates in the head. Although it is unclear that the circuitry governing bursicon release is conserved in both types of fly, this observation is consistent with a mechanism in which bursicon secreted by the $\mathrm{B}_{\mathrm{SEG}}$ acts within the subesophageal ganglion or brain to initiate air ingestion and as a descending signal to promote bursicon secretion from the $\mathrm{B}_{\mathrm{AG}}$. Since disruption of the bursicon signaling pathway only partially attenuates bursicon release from the $\mathrm{B}_{\mathrm{AG}}$, as reported previously by Baker and Truman (2002), other regulatory signals must also exist.

\section{Bursicon promotes $\mathrm{B}_{\mathrm{AG}}$ cell death}

Our discovery that the apoptosis of $\mathrm{B}_{\mathrm{AG}}$ neurons is delayed in rickets mutants indicates that bursicon promotes cell death in the CNS, as it does in the wing (Kimura et al., 2004). Draizen et al. (1999) have shown that apoptosis of the $\mathrm{B}_{\mathrm{AG}}$ and other CCAPexpressing neurons in the ventral ganglia is regulated by declining titers of 20-hydroxyecdysone (20E), which induces expression of the cell death genes reaper and hid. Bursicon presumably facilitates one or more steps in this process. Promotion of apoptosis may, in fact, be a general role of bursicon in the CNS, given that Kimura and Truman (1990) have shown that many neurons in the thoracic and abdominal ganglia die after eclosion in response to a head-derived signal, the release of which correlates closely with wing expansion. Further work will be required to test this hypothesis, but since the circuitry and musculature required for molting is substantially eliminated after eclosion (Cottrell, 1962b; Kimura and Truman, 1990; Draizen et al., 1999), it would be parsimonious if bursicon, which mediates the final physiological events of the terminal molt, were also to facilitate the demise of this machinery.

In summary, our results provide key insights into the cellular mechanisms underlying bursicon's regulation of wing expansion in Drosophila. Because wing expansion follows adult ecdysis, bursicon's release is almost certainly modulated by the hormones that govern the events underlying that process. A remaining challenge is thus to understand the integrative mechanisms that coordinate the release of bursicon with that of ecdysis-related hormones, such as ecdysis-triggering hormone and eclosion hormone. The functional architecture of the bursicon system described here should inform these investigations and help elucidate the cellular circuitry that more generally mediates somatic and behavioral coordination during the ecdysis and postecdysis phases. Our results demonstrate that bursicon contributes more globally to postecdysis than originally imagined.

\section{References}

Bainbridge SP, Bownes M (1981) Staging the metamorphosis of Drosophila melanogaster. J Embryol Exp Morphol 66:57-80.

Baker JD, Truman JW (2002) Mutations in the Drosophila glycoprotein hormone receptor, rickets, eliminate neuropeptide-induced tanning and selectively block a stereotyped behavioral program. J Exp Biol 205:2555-2565.

Cottrell CB (1962a) Imaginal ecdysis of blowflies - control of cuticuar hardening and darkening. J Exp Biol 39:395-412.

Cottrell CB (1962b) Imaginal ecdysis of blowflies-observations on hydrostatic mechanisms involved in digging and expansion. J Exp Biol 39:431-448.

Cottrell CB (1962c) Imaginal ecdysis of blowflies_-evidence for a change in mechanical properties of cuticle at expansion. J Exp Biol 39:449-458.

Dai L, Dewey EM, Zitnan D, Luo CW, Honegger HW, Adams ME (2008) Identification, developmental expression, and functions of bursicon in the tobacco hawkmoth, Manduca sexta. J Comp Neurol 506:759-774.

Davis MM, O'Keefe SL, Primrose DA, Hodgetts RB (2007) A neuropeptide hormone cascade controls the precise onset of post-eclosion cuticular tanning in Drosophila melanogaster. Development 134:4395-4404.

Dewey EM, McNabb SL, Ewer J, Kuo GR, Takanishi CL, Truman JW, Honegger HW (2004) Identification of the gene encoding bursicon, an insect 
neuropeptide responsible for cuticle sclerotization and wing spreading. Curr Biol 14:1208-1213.

Draizen TA, Ewer J, Robinow S (1999) Genetic and hormonal regulation of the death of peptidergic neurons in the Drosophila central nervous system. J Neurobiol 38:455-465.

Ewer J (2007) Neuroendocrinology of eclosion. In: Invertebrate neurobiology (North G, Greenspan RJ, eds), pp 555-579. Cold Spring Harbor, NY: Cold Spring Harbor Laboratory.

Fraenkel G, Hsiao C (1962) Hormonal and nervous control of tanning in the fly. Science 138:27-29.

Fraenkel G, Hsiao C (1965) Bursicon, a hormone which mediates tanning of the cuticle in the adult fly and other insects. J Insect Physiol 11:513-556.

Fraenkel G, Su J, Zdarek J (1984) Neuromuscular and hormonal-control of post-eclosion processes in flies. Arch Insect Biochem Physiol 1:345-366.

Honegger HW, Market D, Pierce LA, Dewey EM, Kostron B, Wilson M, Choi D, Klukas KA, Mesce KA (2002) Cellular localization of bursicon using antisera against partial peptide sequences of this insect cuticlesclerotizing neurohormone. J Comp Neurol 452:163-177.

Kimura K, Kodama A, Hayasaka Y, Ohta T (2004) Activation of the cAMP/ PKA signaling pathway is required for post-ecdysial cell death in wing epidermal cells of Drosophila melanogaster. Development 131:1597-1606.

Kimura KI, Truman JW (1990) Postmetamorphic cell death in the nervous and muscular systems of Drosophila melanogaster. J Neurosci 10:403-411.

Luan H, Lemon WC, Peabody NC, Pohl JB, Zelensky PK, Wang D, Nitabach MN, Holmes TC, White BH (2006) Functional dissection of a neuronal network required for cuticle tanning and wing expansion in Drosophila. J Neurosci 26:573-584.

Luo CW, Dewey EM, Sudo S, Ewer J, Hsu SY, Honegger HW, Hsueh AJ (2005) Bursicon, the insect cuticle-hardening hormone, is a heterodimeric cystine knot protein that activates $\mathrm{G}$ protein-coupled receptor LGR2. Proc Natl Acad Sci U S A 102:2820-2825.

McGuire SE, Mao Z, Davis RL (2004) Spatiotemporal gene expression targeting with the TARGET and gene-switch systems in Drosophila. Sci STKE 2004:pl6.

Mendive FM, Van Loy T, Claeysen S, Poels J, Williamson M, Hauser F, Grimmelikhuijzen CJ, Vassart G, Vanden Broeck J (2005) Drosophila molting neurohormone bursicon is a heterodimer and the natural agonist of the orphan receptor DLGR2. FEBS Lett 579:2171-2176.
Mills RR, Mathur RB, Guerra AA (1965) Studies on the hormonal control of tanning in the American cockroach-I. Release of an activation factor from the terminal abdominal ganglion. J Insect Physiol 11:1047.

O'Brien MA, Taghert PH (1998) A peritracheal neuropeptide system in insects: release of myomodulin-like peptides at ecdysis. J Exp Biol 201:193-209.

Park JH, Schroeder AJ, Helfrich-Förster C, Jackson FR, Ewer J (2003) Targeted ablation of CCAP neuropeptide-containing neurons of Drosophila causes specific defects in execution and circadian timing of ecdysis behavior. Development 130:2645-2656.

Reynolds SE (1977) Control of cuticle extensibility in wings of adult Manduca at time of eclosion-effects of eclosion hormone and bursicon. J Exp Biol 70:27-39.

Taghert PH, Truman JW (1982) Identification of the bursicon-containing neurones in abdominal ganglia of the tobacco hornworm, Manduca sexta. J Exp Biol 98:385-401.

Truman JW (1973) Physiology of insect ecdysis. 3. Relationship between hormonal control of eclosion and of tanning in tobacco hornworm, Manduca sexta. J Exp Biol 58:821-829.

Truman JW (2005) Hormonal control of insect ecdysis: endocrine cascades for coordinating behavior with physiology. Vitam Horm 73:1-30.

Truman JW, Endo PT (1974) Physiology of insect ecdysis: neural and hormonal factors involved in wing-spreading behaviour of moths. J Exp Biol 61:47-55.

Truman JW, Thorn RS, Robinow S (1992) Programmed neuronal death in insect development. J Neurobiol 23:1295-1311.

White BH, Osterwalder TP, Yoon KS, Joiner WJ, Whim MD, Kaczmarek LK, Keshishian H (2001) Targeted attenuation of electrical activity in Drosophila using a genetically modified $\mathrm{K}(+)$ channel. Neuron 31:699-711.

Wong AM, Wang JW, Axel R (2002) Spatial representation of the glomerular map in the Drosophila protocerebrum. Cell 109:229-241.

Zhao T, Gu T, Rice HC, McAdams KL, Roark KM, Lawson K, Gauthier SA, Reagan KL, Hewes RS (2008) A Drosophila gain-of-function screen for candidate genes involved in steroid-dependent neuroendocrine cell remodeling. Genetics 178:883-901.

Zitnan D, Kim YJ, Zitnanová I, Roller L, Adams ME (2007) Complex steroid-peptide-receptor cascade controls insect ecdysis. Gen Comp Endocrinol 153:88-96. 